\title{
LA REPRESENTACIÓN HISTORIOGRÁFICA DE LA GUERRA EN EL MAR EN EL LARGO SIGLO XVIII: PENSAMIENTO TÁCTICO Y ESTRATÉGICO, NAVALISMO HISTÓRICO Y METODOLOGÍAS DE VANGUARDIA EN EL SIGLO XXI
}

\author{
The Historiographical Representation of Spanish Naval \\ Warfare during the Long XVIIth Century: Tactical and \\ Strategic Thought, Historical Navalism and Naval \\ Historiography in the XxIst Century
}

\author{
Iván VALDEZ-BUBNOV \\ Universidad Nacional Autónoma de México \\ ivanvaldezbubnov@yahoo.com
}

Fecha de recepción: 17/12/2019

Fecha de aceptación definitiva: 18/06/2020

RESUMEN: El presente ensayo tiene por objetivo comprender de manera selectiva la evolución de la historiografía dedicada a la guerra en el mar durante el largo siglo XVIII hispano, en función de su separación de la teoría táctica y estratégica desarrollada hacia finales de ese período; de su intersección con el desarrollo de los estudios estratégicos durante el siglo XIX; y de su ulterior desarrollo durante el siglo xx bajo la influencia del navalismo histórico. En segunda instancia, el estudio tiene por objeto comprender su evolución ulterior, a partir de la crítica interpretativa generada por los estudios de táctica y estrategia naval dieciochista en Francia y Gran Bretaña, y, finalmente, de la evolución de las corrientes historiográficas de vanguardia en la historia militar/naval entre los siglos XX y XXI, específicamente, las teorías de la Revolución Militar, los conceptos de Estado Fiscal-Militar, Fiscal-Naval, $\mathrm{y}$ «Estado Contratante» o «Contractor State». 
Palabras clave: estrategia naval; táctica naval; navalismo histórico; Revolución Militar; Estado Fiscal-Militar; Contractor State.

ABSTRACT: The subject of the present essay is the historiographical representation of Spanish naval warfare in the long XVIIIth century, based the theoretical separation of the concept of "strategy" from the previous, wider concept of "tactics". It aims at showing the origins of Spanish late XVIIIth-century definition of "naval strategy», conceived as a scientific method for the planning of naval operations based on the study of history. It also traces the influence of strategic studies in Spanish naval historiography during the XIXth and XXth centuries as well as its connection with the international development of military and naval historiography during the xxIst century.

Key words: Spanish naval strategy; Spanish naval tactics; Military Revolution; Fiscal-Military State; Contractor State.

\section{INTRODUCCIÓN}

El presente ensayo bibliográfico tiene tres objetivos. El primero es comprender el contexto hispano del estudio teórico de la guerra naval durante el largo siglo XVIII, tanto en su dimensión táctica como estratégica. El segundo objetivo se deriva del primero, y es trazar la influencia de los estudios estratégicos en la historiografía naval hispana de los siglos XIX y XX. El tercer objetivo es ofrecer un esbozo de la forma en que el pensamiento naval en la historiografia del siglo XXI ha trascendido la orientación metodológica de esas dos etapas formativas, intersectando con los estudios internacionales sobre la relación entre la guerra, la fiscalidad pública y la construcción del Estado. Para ello, es preciso considerar que los términos "áctica» y "estrategia" no han sido dotados del mismo significado en todas las épocas y en todos los contextos culturales. En efecto, la historiografía internacional ha señalado, en ejercicios de críticos de profundo alcance, la dificultad de situar el elusivo significado del término «estrategia» como componente específico de la política exterior francesa y británica del siglo XVIII ${ }^{1}$. En efecto, más allá de la mera semántica, este concepto analítico no existía en los procesos de toma de decisión político-militar relativos al uso de fuerzas navales por parte de esos dos gobiernos durante el período señalado, por lo cual, su uso como herramienta analítica debe situarse en el contexto de una profunda identificación entre el

1. DePeyre, Michel. Tactiques et Stratégies Navales de la France et du Royaume-Uni de 1690 à 1815. Paris: Ed. Economica, 1998, p. 5; RODGER, Nicholas. "The idea of Naval Strategy in Britain in the Eighteenth and Nineteenth Centuries». En Till, Geoffrey (ed.). The Development of British Naval Thinking. London: Routledge, 2006, pp. 19-33; CHALINE, Olivier. «Strategy Seen from the Quarterdeck in the Eighteenth-Century French Navy». En Dancy, J. Ross; Darnell, Benjamin; Rodger, N. A. M. y Wilson, Evan (eds.). Strategy and the Sea. Essays in Honour of John B. Hattendorf. Woodbridge: The Boydell Press, 2016, pp. 19-27. 
desarrollo de los estudios históricos y el surgimiento de la teoría militar/naval propia de la segunda mitad del siglo XIX. Fue entonces cuando el legado de la teoría militar derivada de las guerras napoleónicas fue plenamente transferido al estudio de la historia naval, dando lugar al surgimiento de los estudios estratégicos propiamente dichos. En otras palabras, el uso del término "estrategia", en el contexto del estudio de la experiencia militar y naval del siglo XVIII, debe ser reconocido como un anacronismo metodológico deliberado, utilizado para generar una abstracción temática que puede resultar útil para interpretar el pasado desde la perspectiva de nuestro presente, pero que ciertamente no debería ser comprendido como uno de los elementos constitutivos del pensamiento de ese período. Esta crítica puede ser puntualmente transferida al contexto hispano. En efecto, desde el punto de vista semántico, no existe duda de que, durante el siglo XVIII, el término "estrategia» no era utilizado en procesos de toma de decisión política o en la planeación de un conflicto. Desde el punto de vista analítico, sin embargo, el panorama es más complejo, pues existe una vertiente de tratadística técnica, escasamente conocida, que permite entrever los primeros pasos de un proceso intelectual específicamente hispano que habría de definir una definición teórica, separada de la táctica y de su dimensión operacional, conducente al concepto moderno de "estrategia».

La profunda identificación entre la definición teórica de la estrategia y la escritura de la historia representa un fenómeno cultural en plena forma, pocas veces identificado y reconocido como tal, y la dificultad de precisar las fronteras entre ambos conceptos -pensamiento estratégico e historiografía- ha resultado en una orientación temática y metodológica precisa en el estudio académico de la guerra naval y, ciertamente, también en su proyección mediática y popular: el énfasis en la disposición ofensiva, la potencia de fuego y el encuentro de aniquilación como objetivo de la estrategia, subsumidos en el difuso concepto de "control del mar». Desde una perspectiva temática, esto generó una importante desproporción entre los estudios dedicados a la dimensión operacional del poder naval centralizado en la forma de la flota de batalla y sus auxiliares, y aquellos dedicados a la práctica descentralizada en la guerra en el mar, en la forma del corso empresarial y el corso de Estado. El impacto en nuestro conocimiento acerca de la evolución de la táctica también es perceptible: el énfasis metodológico se encuentra en los mecanismos de centralización de los sistemas de mando y control, es decir, en la forma de la táctica formal descrita en la tratadística de la época, antes que la descentralización de los dispositivos tácticos y la transferencia de la iniciativa a los comandantes individuales. Desde una perspectiva cronológica, estos fenómenos redundaron en una notable desproporción entre los numerosos estudios dedicados a la evolución del pensamiento estratégico posterior a la guerra de los Siete Años y en una comparativa escasez de publicaciones acerca de los usos del poder naval entre los siglos XVII y XVIII. Todo esto indica que el modelo británico de fines del siglo XVIII fue percibido por generaciones de historiadores y aficionados como el paradigma mismo de la guerra naval, como el criterio último de la eficacia estratégica y como el rasero con que debía ser medido el desempeño de los sistemas navales 
LA REPRESENTACIÓN HISTORIOGRÁFICA DE LA GUERRA EN EL MAR EN EL LARGO SIGLO XVIII...

borbónicos durante el largo siglo XVIII, en detrimento de la comprensión de los objetivos que sus creadores, teóricos y prácticos, buscaron alcanzar. El objetivo ulterior del presente ensayo es comprender cómo la superación de este problema metodológico ha generado una importante renovación de la historiografía naval dedicada al pensamiento estratégico en el mundo hispano, entre los siglos Xx y XXI.

\section{TÁCTICA TEÓRICA Y «POLÍTICA NAVAL» ENTRE LOS SIGLOS XVII Y XVIII: VeITIA LINAGE, VAUBAN Y GERÓNIMO DE UZTÁRIZ}

La primera obra que contiene una reflexión explícita al respecto del uso de las innovaciones tácticas y tecnológicas generadas por las guerras Anglo-Holandesas (1652-54, 1665-67 y 1672-74), en un contexto hispano, es el Norte de la Contratación de las Indias Occidentales, de Joseph de Veitia y Linage (1672). Este texto señala la adopción de la "línea de batalla» como formación derivada del fuego de artillería de andana como dispositivo táctico principal, así como el abandono de la formación en línea de frente, derivada de la antigua táctica de galeras y veleros artillados. Por otra parte, la primera obra del siglo XVIII español que contiene lo más próximo a un discurso de estrategia naval es la Theórica y práctica de comercio $y$ de marina, del militar y economista navarro Gerónimo de Uztáriz (1724). Este libro contiene una definición discursiva de los objetivos políticos y económicos del primer gobierno borbónico español, así como una valoración precisa de la forma en que las fuerzas navales podían ser empleadas en los teatros mediterráneo, atlántico y americano. Incluye también una descripción detallada de la planta de armada necesaria para alcanzar estos objetivos, e incluso la forma en que las escuadras y buques sueltos debían ser empleados a nivel operacional.

Esta visión "estratégica» comprendía no solo las fuerzas navales permanentes, controladas y mantenidas por medio de la infraestructura centralizada del Estado, sino también la dimensión descentralizada de la práctica de la guerra en el mar por parte de las economías marítimas regionales, en la forma de la guerra de corso. Pese a la longeva tradición hispana en el uso del corso marítimo como instrumento estratégico, los referentes de Uztáriz en este rubro son de origen francés, específicamente, la Ordenanza de 1689, la cual, a su vez, recoge las ideas acerca de la guerra marítima descentralizada desarrolladas por el gran arquitecto militar de Luis XIV, Sébastien Le Prestre de Vauban, reunidas en una etapa tardía bajo el título Mémoire sur la caprerie (1695). Con base en este modelo, Uztáriz proponía aprovechar la capacidad de las economías regionales del imperio para participar en la guerra en el mar, por medio de una estrecha interacción con las fuerzas navales del Estado, la cual incluía no solamente el desarrollo de la infraestructura administrativa necesaria para fiscalizar los productos resultantes de la venta de las presas, sino también la posibilidad de que armadores privados operaran buques pertenecientes a la Real Armada. En un sentido convergente, 
LA REPRESENTACIÓN HISTORIOGRÁFICA DE LA GUERRA EN EL MAR EN EL LARGO SIGLO XVIII...

la función central de la flota de batalla debía ser la protección del comercio en el Mediterráneo, el Atlántico y el Caribe, por medio de tres recursos: la disuasión generada por un núcleo de pesados navíos de línea; el despliegue de navíos de dos puentes para el servicio de crucero y para la escolta de los convoyes mercantes; y la persecución del contrabando por parte de buques menores. Por otra parte, las fuerzas navales debían servir también como instrumento para la proyección del poder militar a través de los espacios marítimos, dotando así a la guerra terrestre de un componente significativamente más dinámico que la mera operación de los ejércitos a través de espacios continentales.

Es preciso considerar que la «estrategia naval» de Uztáriz representa solamente un aspecto de un amplio programa de reforma política y económica de las estructuras administrativas heredadas del período Habsburgo. En este sentido, debe ser comprendida como un componente del más vasto concepto de "política naval", constituido, a su vez, como un conjunto de ideas relacionadas con el uso político y económico del mar en un sentido defensivo y proteccionista, en el cual el uso de las fuerzas navales representa un factor subordinado a la protección del comercio y a la proyección del poder militar terrestre. Más aún, la función de la "estrategia» en el pensamiento de Uztáriz era fundamentalmente política, constituyendo parte de un cuerpo doctrinal dirigido a estadistas y no a profesionales o prácticos de la guerra en el mar. En suma, las obras de Joseph de Veitia Linage y Gerónimo de Uztáriz representan dos extremos del pensamiento naval atlántico español, en el cual la táctica artillera derivada de las guerras Anglo-Holandesas, principio fundamental de la batalla de aniquilación llevada a cabo por fuerzas navales especializadas, dio paso a una expresión doctrinal defensiva, concebida para la proyección del poder militar terrestre y centrada, a un mismo tiempo, en la protección y hostilización del comerio marítimo, por medio de la interacción de la flota de batalla con la guerra de corso $^{2}$.

3. Táctica naval geométrica y estrategia científica en el XVIII: De Paul Hoste A HENRY LLOYD

Entre las fechas de publicación de las obras de Veitia y de Uztáriz se encuentra la gestación del gran paradigma de la táctica naval dieciochista, el cual definió la dimensión teórica del pensamiento naval español hasta el siglo XIx: la obra del jesuita francés Paul Hoste, titulada L'Art des Armées Navales ou Traité des Évolutions Navales (Lyon, 1697) ${ }^{3}$. Se trata de un manual concebido como instrumento didáctico para la formación de oficiales, el cual sistematiza diversas formas de evoluciones de

2. VAldez-Bubnov, Iván. «Pensamiento táctico y liderazgo estratégico: la evolución de la doctrina naval española entre los siglos XVII y XVIII. En GUIMERÁ, Agustín (ed.). Liderazgo esdtratégico en España, 1475-2018. Madrid: UNED/Instituto Universitario General Gutiérrez Mellado, pp. 39-41.

3. Hoste, Paul. L'Art des Armées Navales. Lyon: Anisson \& Posuel, 1697. 
LA REPRESENTACIÓN HISTORIOGRÁFICA DE LA GUERRA EN EL MAR EN EL LARGO SIGLO XVIII...

escuadra, divididas en dos conceptos fundamentales: el orden de marcha y el orden de batalla. Esta división permite al autor describir distintas formas de ordenar los componentes individuales de una unidad táctica -la «escuadra»- en función de los principios de caza y retirada, el despliegue entre pasajes costeros y en alta mar. También detalla la relación de estos principios con distintas formas de orden de marcha, así como las posibles formas de intercambio entre ellas y el orden de batalla, en función de los vientos y de las posibilidades de contacto con el enemigo. En este sentido, la descripción de las variantes del orden de marcha se encuentra concebida en función de las posibilidades de configuración del orden de combate desde una posición de ventaja. Como confirmación de este objetivo, el tratado incluye una propuesta de sistema de señales visuales diseñado para coordinar la interacción entre los órdenes propuestos.

La esencia del método de Hoste se encuentra en la relación geométrica entre los órdenes de marcha y de batalla, definida visualmente por líneas compuestas por las posiciones de cada navío dentro de su propia escuadra, y en relación con los navíos del enemigo. Esta narrativa gráfica, constituida por los ángulos generados por las posibles intersecciones entre estas líneas, alcanza un alto nivel de abstracción, sostenido por abundantes ilustraciones y diagramas concebidos para enfatizar una relación aparente entre la táctica naval y la geometría. El elemento unificador de toda esta construcción teórica y gráfica se encontraba en el fuego de artillería de andana como instrumento táctico decisivo - "presentar el costado»-, así como el aprovechamiento de la formación en línea de fila -la "línea de batalla»- para transferir sus principios a la actuación conjunta de toda la escuadra, en un sentido siempre paralelo a la formación de la escuadra enemiga. En suma: el pensamiento de Hoste representa una sistematización de la experiencia táctica derivada de las guerras Anglo-Holandesas, presentada con un altísimo grado de abstracción y complejidad conceptual, cuya intención explícita era instruir a los comandantes navales en la práctica de la guerra en el mar. Es importante enfatizar aquí la dimensión puramente táctica de este objetivo: el tratado no aspira, a diferencia de la obra de Uztáriz, a definir ningún principio para interpretar el uso de las fuerzas navales en una campaña o en un conflicto, más allá de la dimensión concreta del contacto con el enemigo y, en este sentido, representa una sistematización extrema y altamente compleja de los principios inicialmente señalados por Veitia, en el contexto hispano.

\section{TÁCTICA Y ESTRATEGIA GEOMÉTRICA EN EL PENSAMIENTO MILITAR EUROPEO EN EL SIGLO XVIII}

La consolidación de la táctica geométrica en el pensamiento naval español debe ser comprendida en el contexto de la evolución general del pensamiento militar europeo, el cual tendió, a partir de la segunda mitad del siglo XVIII, hacia una nueva abstracción de principios definida por un ámbito operacional de dimensión 
LA REPRESENTACIÓN HISTORIOGRÁFICA DE LA GUERRA EN EL MAR EN EL LARGO SIGLO XVIII...

superior a la táctica. Durante este período, el continuado interés de los estudiosos en la tratadística antigua, heredado de la literatura militar del Renacimiento, dio gradualmente paso a estudios teóricos basados en el estudio de los conflictos de la época, en los cuales el concepto grecolatino de «estrategia», comprendido hasta entonces como el arte del generalato, comenzó a ser definido como la búsqueda y definición "científica" de reglas y principios de alcance universal, derivados del estudio de la táctica y caracterizados como la "parte sublime" de la guerra ${ }^{4}$.

Estas ideas intersectaron con la transferencia a los estudios de historia militar de la metodología desarrollada en el arte de la fortificación y el asedio por Sebastién Le Prestre de Vauban, ya mencionado en el contexto de la guerra naval descentralizada de entresiglos y el papel de la guerra de corso en la "política naval» de Gerónimo de Uztáriz. La narrativa geométrica de Vauban, derivada de la exactitud geométrica de la arquitectura militar y el poder explicativo del trazado lineal de sus ilustraciones, tuvo, para los estudiosos de la guerra terrestre, un efecto semejante al que tuvo la obra de Hoste entre los estudiosos de táctica naval. Así, la descripción geométrica generó gradualmente un cambio de actitudes entre los teóricos del arte militar, basado en la abstracción atemporal de principios prácticos derivados de la experiencia histórica. Este principio de abstracción narrativa o gráfica comenzó a ser percibido como la confirmación de la naturaleza supuestamente "científica» de la teoría militar".

Durante la guerra de los Siete Años, la admiración generada por el éxito de Federico II de Prusia en evitar batallas campales en condiciones de inferioridad condujo a que la atención de los teóricos se enfocara en abstraer de manera "científica" las claves de sus campañas, las cuales comenzaron a ser explicadas como un "sistema" específicamente prusiano ${ }^{6}$. Esta tendencia se encuentra sintetizada en la obra del soldado de fortuna galés Henry Lloyd, quien sirvió en los ejércitos prusiano, austríaco, ruso y francés en distintas fases de ese conflicto. Su primera obra, History of the Late War in Germany (1766), representa una detallada historia operacional a nivel táctico, seguida de una reflexión teórica tendiente a la abstracción de principios operativos a partir de la experiencia histórica. Este método alcanzó su pleno desarrollo en las memorias del mismo autor, publicadas en $1781^{7}$. En

4. Gat, Azar. The Origins of Military Thought from the Enlightenment to Clausewitz. Oxford: University Press, 1989, pp. 30-43.

5. Vauban, Sébastien Le Prestre. De l'attaque et de Ia defense des places. Pierre de Hondt, 1737.

6. Véase PAlmer, R. R. "Frederick the Great, Guibert, Bulow: From Dynastic to National War". En PARET, Peter. Makers of Modern Strategy. Princeton: University Press, 1986, pp. 91-122. Para el archiduque, véase Eysturlid, Lee W. The Formative Influences, Theories and Campaigns of the Archule Carl of Austria. London: Greenwood Press, 2000.

7. Las obras completas de Lloyd han sido editadas recientemente en un solo volumen: SPEELMAN, Patrick (ed.). War, Society and the Enlightenment: the Works of General Henry Lloyd. Leiden: Brill, 2005. Para un estudio detallado, véase del mismo autor: Henry Lloyd and the Military Enlightenment of Eighteenth-Century Europe. Londres: Praeger, 2002. 
conjunto, las ideas de Lloyd constituyen un verdadero modelo teórico concebido para abstraer los principios fundamentales de la guerra terrestre de su contexto histórico, definiendo un corpus prescriptivo para la planeación y ejecución "científica» de las operaciones militares por medio de la narrativa geométrica heredada de Vauban. Su originalidad reside en la transición desde un método analítico centrado en la organización de las tropas, la administración de la logística y el contacto con el enemigo (es decir, el sentido grecolatino del término "táctica») hacia la conducta general de la maniobra, en un sentido de amplitud superior a las particularidades del combate, y dirigido hacia la planeación y ejecución de toda una campaña (el sentido moderno del término "estrategia»). Es precisamente en este segundo sentido que los estudios históricos de Lloyd han sido considerados por los especialistas como fundamento de los estudios estratégicos contemporáneos.

Para Lloyd, la dimensión puramente filosófica de la teoría militar podía ser trascendida por medio de la caracterización de la estrategia como un «arte». En efecto, pese a que los principios fundamentales de la guerra podían ser sintetizados y separados de su contexto histórico y, por ende, aprehendidos por medio del estudio de la narrativa geométrica, su aplicación exitosa en condiciones concretas dependía del genio intuitivo y personal del comandante. En este sentido, la nueva "estrategia geométrica" de Lloyd puede ser vista como una herramienta concebida para disciplinar la percepción subjetiva de las condiciones materiales que definen la práctica de la guerra. Estas condiciones quedaban constituidas por la base logística que hacía posible el aprovisionamiento del ejército, la naturaleza del terreno en que podía operar y la situación del enemigo en relación con ambas. Así, la articulación de la estrategia en función de estas variables quedó subsumida en el concepto geométrico de "líneas de operación", cuyo uso práctico, a su vez, aparecía definido por las posibilidades de movimiento de las tropas en función de las particularidades geográficas del terreno. De esta forma, la sistematización del conocimiento geográfico emergió como el referente concreto para la transferencia de los principios geométricos derivados de las técnicas de fortificación y asedio a la planeación del movimiento de los ejércitos, constituyendo el fundamento de una nueva retórica cientificista, tendiente a trascender la mera dimensión táctica hacia un nivel operacional más amplio, definido por las posibilidades concretas del teatro de operaciones. En conjunto, estas ideas tendieron hacia la caracterización de la estrategia como un fenómeno científicamente aprehensible, representado por el método geométrico, susceptible de ser aprehendido por medio del genio individual del comandante, y ejecutado, de manera ideal, con predominio de la maniobra sobre el combate, abriendo la posibilidad de la planeación y ejecución de campañas potencialmente incruentas.

La separación conceptual de la táctica y la estrategia por medio de la abstracción de su contexto histórico, su concreción en la cartografía y su descripción visual y narrativa a través del método geométrico constituyen la esencia del pensamiento militar europeo posterior a la guerra de los Siete Años, y se encuentran presentes en la obra de varios autores, en particular, el crítico de Lloyd, Georg 
LA REPRESENTACIÓN HISTORIOGRÁFICA DE LA GUERRA EN EL MAR EN EL LARGO SIGLO XVIII...

Friedrich Von Tempelhoff (1737-1807); el archiduque Karl de Austria (1771-1847); y el más radical promotor del método geométrico, el prusiano Dietrich Heinrich Von Bülow (1757-1807). Todos estos autores, además de Lloyd, reclamaron para sí, y obtuvieron de distintos biógrafos, la primacía en la invención de la «estrategia científica». Con ello, la idea de la existencia de principios invariables en la práctica de la guerra, definidos por la geografía y las condiciones de los teatros de operaciones, aunada a la capacidad intuitiva para hacer posible su uso práctico en sustitución de la batalla por la maniobra, quedaron constituidas como la "parte sublime» del pensamiento militar dieciochista, a nivel europeo.

\section{TÁCTICA GEOMÉTRICA Y ESTRATEGIA CIENTÍFICA EN EL PENSAMIENTO NAVAL ESPAÑOL ENTRE LOS SIGLOS XVIII Y XIX}

En 1723, Juan Joseph Navarro de Viana y Búfalo (1687-1772), oficial encargado de la formación de los cadetes en la Academia de Guardias Marinas de Cádiz, dio inicio a una traducción ilustrada de la obra de Hoste, bajo el título de Evoluciones navales. De igual forma, Navarro produjo una cantidad significativa de manuscritos ilustrados como apoyo didáctico para la docencia en la Academia, derivados en gran parte del estudio de la obra de $H_{0} e^{8}$. Esta filiación doctrinal se consolidó a partir de su experiencia práctica en las campañas de Cerdeña (1717-18), Orán (1732) e Italia (1742-44), en las cuales tuvo bajo su mando fuerzas compuestas en gran parte por mercantes armados, según la doctrina estratégica de Uztáriz, cuyo desempeño ante los navíos de línea británicos marcó profundamente la evolución ulterior de su pensamiento táctico?.

En efecto: en una serie de manuscritos producidos entre 1747 y los años posteriores a la guerra de los Siete Años, Navarro radicalizó su adopción de la doctrina táctica de Hoste, promoviendo una política tecnológica concebida para incrementar la potencia de fuego de los navíos por medio de una especialización de funciones concebida a partir de los preceptos de la línea de batalla, y manifiesta en el incremento del peso de la andanada de las baterías principales de las unidades superiores a las fragatas, así como en el incremento en la proporción de los tipos de tres puentes en la configuración de la planta de la Real Armada. Todo esto indica una separación significativa de los preceptos de Uztáriz, los cuales, como

8. Véanse VV. AA. "D. Juan José Navarro Marqués de la Victoria en la España de su tiempo". Cuadernos Monográficos del Instituto de Historia y Cultura Naval, 1996, 28. O’Donnell, Hugo. El primer Marqués de la Victoria, personaje silenciado en la reforma dieciochesca de la Armada. Madrid: Real Academia de La Historia, 2004, y «El Marqués de la Victoria, una opinión discordante con la política naval de Ensenada». Anuario de Estudios Atlánticos, 2008, pp. 13-41.

9. VALDEZ-BuBNOv, Iván. "La Batalla de Cabo Sicié. Implicaciones logísticas y doctrinales del uso de mercantes armados en servicio naval». En BAudot, María. El Estado en guerra. Madrid: Polífemo, 2014, pp. 117-136. 
LA REPRESENTACIÓN HISTORIOGRÁFICA DE LA GUERRA EN EL MAR EN EL LARGO SIGLO XVIII...

hemos señalado, partían de una estrecha interacción con el comercio, el corso de Estado y la proyección del poder militar a través de los espacios marítimos.

Estas ideas representan la esencia del pensamiento táctico español de la segunda mitad del siglo XVIII, siendo desarrolladas por otros autores y erigidas en doctrina oficial por las Ordenanzas de Armada de 1748 y 1793. Su ulterior desarrollo conceptual se encuentra reflejado en los Rudimentos de táctica naval, de Joseph de Mazarredo y Salazar, obra que recupera nuevamente la estructura y contenidos de la obra de Hoste a partir de las variantes de la relación entre los órdenes de marcha y de batalla, apoyada por una prolija sucesión de diagramas geométricos ${ }^{10}$. Dada la marginación relativa de Navarro de la alta política de la Secretaría de Marina durante los años de su más vigoroso impulso literario, además de su fallecimiento cuatro años antes de la publicación de la obra de Mazarredo, es posible considerar a este último como la influencia definitoria en el pensamiento táctico español de la segunda mitad de la centuria.

\section{LA CRISIS DE LA TÁCTICA GEOMÉTRICA EN EL PENSAMIENTO NAVAL ESPAÑOL ENTRE LOS SIGLOS XVIII Y XIX}

El andamiaje intelectual construido por los teóricos navales y militares a lo largo del siglo XVIII fue barrido por el advenimiento de la Revolución francesa y la guerra ideológica total, a partir de 1792. La transformación de la política revolucionaria en dictadura militar y, finalmente, en monarquía expansiva, diseminó por toda Europa las nuevas realidades de la movilización total de la sociedad para la guerra, el abandono de la administración logística en aras del pillaje y la búsqueda de la batalla decisiva como objetivo último de la estrategia. En este contexto, el pensamiento naval español experimentó una transformación que apuntaría al cuestionamiento doctrinal de la táctica geométrica de Hoste, Navarro y Mazarredo, así como al surgimiento de un nuevo concepto de estrategia naval científica.

Desde el punto de vista táctico, este viraje se encuentra reflejado en el manuscrito inédito titulado Reflexiones..., escrito por el entonces secretario del Despacho Universal de Marina, Domingo de Grandallana, poco antes de la batalla de Trafalgar $(1805)^{11}$. Como otras fuentes españolas de este período - piénsese en las ideas de Antonio de Escaño- su estructura parte de una comparación de la

10. Mazarredo, José de. Rudimentos de táctica naval. Madrid: Joaquín Ibarra, 1776. Véase «José de Mazarredo y Salazar. Cuadernos Monográficos del Instituto de Historia y Cultura Naval, 1996, 28.

11. Madrid: Biblioteca del Palacio Real, Ms. 11/1292. Existe una copia en el Museo Naval de Madrid. Las ideas de Grandallana fueron publicadas en: Tratado de señales de día y de noche, e hipótesis de ataques y defensas. Madrid: Imprenta Real, 1804. Parte de sus contenidos descritos en AlCALÁ Galiano, Pelayo. El combate de Trafalgar. Madrid: Instituto de Historia y Cultura Naval, 2003. La primera edición es de 1909. 
Armada española con las marinas francesa y británica ${ }^{12}$. Para los propósitos del presente ensayo, su interés reside en las opiniones de su autor al respecto de la táctica geométrica, derivadas de su experiencia de mando en la defensa de Cádiz contra el almirante británico Rodney (1780); en la batalla del Cabo Espartel, contra Howe (1782); en la defensa de Tolón contra Bonaparte (1793); y la defensa de Cádiz contra Nelson (1798), entre otras acciones. De manera literal, el documento expresa no solo una desaprobación total de la "táctica geométrica» por «la regularidad y precisión de sus movimientos», sino también de los sistemas de señales asociados a ella. En efecto, Grandallana declaró reflejar una opinión generalizada entre la oficialidad naval española cuando, al reflexionar sobre el mando de una escuadra en combate, encontró notables defectos en "las doctrinas sobre que se habían de sustentar aquellas grandes operaciones", las cuales habían sido "aprobadas y seguidas por tantos y tan sabios Generales como me han precedido". Esto le condujo "a leer con empeño la historia de la guerra en el mar" para llevar a cabo un estudio particular de la táctica naval española, la cual halló definida por la doctrina francesa, a diferencia de la práctica de los británicos. Así, en el estudio de la táctica y la legislación de las tres armadas atlánticas, consideró haber encontrado, "sin ofensa de nadie», el origen de su distinto desempeño en combate.

Grandallana criticó la doctrina táctica consistente en la convergencia de toda maniobra en la línea de batalla, con el único expediente decisivo de usar la superioridad numérica de la escuadra atacante para doblar la línea enemiga con los navíos que excediesen el paralelo de las escuadras enfrentadas o para cortarla. Esta reflexión le condujo a una crítica directa a la tratadística francesa derivada de la obra de Hoste, la cual, según el autor, presuponía la superioridad numérica como condición necesaria para la ejecución de estas maniobras ofensivas. Más aún, Grandallana criticaba los presupuestos de la táctica geométrica situándolos en el terreno de la fantasía, cuya única utilidad práctica podía residir en el entrenamiento, pero no en el combate. Así, consideraba un "principio equivocado" suponer que el rigor de la formación en cuerpos y la sujeción de los navíos individuales a la línea de batalla tendría efectos de análoga precisión en un encuentro. Más aún, obligar a los comandantes a mantener una posición fija era contraproducente, pues esto, una vez trabado el combate, impedía el uso de la iniciativa (la "obstrucción de sus facultades») para explotar situaciones favorables, asumiendo, "también de manera errónea", que todo el encuentro podía ser controlado por el almirante o el jefe de la escuadra. En este sentido, censuraba la práctica de transferir el puesto de comando a una fragata, lo cual concretaba la creencia de que su separación del combate debía conferir una mayor capacidad de controlarlo a distancia. Esta apología de la iniciativa individual como antítesis de la rígida formalidad de la

12. Guimerá, Agustín. "Imitando al enemigo: el plan de reforma naval de Antonio de Escaño (1807)». En MARTín-Merás, María Luisa (ed.). Navigare Necesse Est. Estudios de Historia Marítima en bonor de Lola Higueras. Gijón: Fundación Alvargonzález, 2008, pp. 315-335. 
LA REPRESENTACIÓN HISTORIOGRÁFICA DE LA GUERRA EN EL MAR EN EL LARGO SIGLO XVIII...

táctica geométrica quedaba sintetizada en una pregunta retórica que merece ser recordada por la historia de la táctica naval: «¿No sería mejor que cada cual fuese tan guapo como quisiese?».

En conjunto, las ideas de Grandallana representan una censura frontal de las Ordenanzas de Armada de 1748 y 1793, las cuales especificaban procedimientos disciplinarios para los oficiales culpables de abandonar la línea de batalla o de no formarla. Esta crítica se extiende al perfeccionamiento de los sistemas de señales, concebidos en torno a la idea de hacer más eficiente la pluralidad de principios de maniobra en función de un solo dispositivo táctico: la formación forzada de la línea de batalla como único medio que presenta la táctica geométrica. Como contraparte, el autor proponía que la única normativa táctica estuviese constituida por las instrucciones dadas por un jefe de escuadra a sus subalternos antes del combate. Por otra parte, percibía también que el éxito de la táctica inglesa consistía en atacar con superioridad numérica una porción de la fuerza enemiga, concentrando así una mayor potencia de fuego en contra de un solo punto vulnerable en su formación, para después batir a la totalidad en detalle. Esto hacía posible, según una serie de ejemplos históricos citados por el autor, que un combate pudiera ser favorablemente decidido por una fuerza atacante sin contar con superioridad numérica. Nada más claro que sus propias palabras: «El negocio no es la formación, sino vencer al enemigo...".

\section{El SURGIMIENTO DE LA «CIENCIA NUEVA» DE LA ESTRATEGIA NAVAL ESPAÑOLA}

La crítica española a la vertiente naval de la táctica geométrica tuvo lugar de manera paralela a la invención del concepto moderno de "estrategia naval», en un contexto propiamente hispano. En 1804, Enrique Reynaldo Macdonnell y de Gondé (1753-1823), entonces brigadier de la Armada con un importante historial de servicio en la guerra de Independencia de Estados Unidos y en la guerra ruso-sueca de 1788-90, hizo entrega a la Secretaría de Marina de un voluminoso manuscrito conteniendo un detallado plan de campaña terrestre y naval concebido para resolver los problemas diplomáticos del imperio español en América del norte ${ }^{13}$. Este plan se hallaba formulado de manera conjunta con una teoría explícita de la estrategia naval, definida como una disciplina abstracta, separada de las condiciones históricas y de las particularidades de la táctica. Hasta ahora, este manuscrito ha sido objeto de un estudio historiográfico detallado, al cual remitimos con el fin de evitar aquí la repetición de los contenidos de sus dos planes de campaña ${ }^{14}$. En este apartado nos enfocaremos en la dimensión propiamente teórica de su contenido.

13. Madrid, Museo Naval, MS. 435, Doc. 1.

14. Valdez-Bubnov, Iván. "Spanish Naval Strategy and the United States, 1763-1819". The Mariner's Mirror, 2015, 101: 1, pp. 4-20. 
El manuscrito de Macdonnell contiene la primera aparición del concepto moderno de "estrategia naval» no solo en la tratadística hispana, sino también en la de otras potencias atlánticas. Claramente, el autor se hallaba consciente de esta primacía: pese al hecho de que un rasgo común a la tratadística militar teórica del siglo XVIII era el reclamo en la paternidad en el uso militar del método "científico", en el caso de Macdonnell esta pretensión se cumple, debido a la transferencia al ámbito naval de la separación conceptual entre la estrategia y la táctica. Esta transferencia fue explícita: para Macdonnell, las operaciones de la guerra en el mar debían considerarse "tan sublimes y delicadas y de tanta importancia" como las de tierra. El autor se hallaba plenamente consciente de esta novedad, al comparar sus ideas con la literatura militar teórica francesa y británica de su tiempo.

El pensamiento de Macdonnell revela un alto grado de sofisticación, que ciertamente le coloca en la cúspide de la tratadística militar y naval de la segunda mitad del siglo XVIII. Su propósito práctico era alcanzar una serie de objetivos políticos y diplomáticos que permitiesen conservar la integridad territorial del imperio español en el norte de América y salvaguardar sus intereses económicos en el resto de ese continente. Así, sus ideas sobre estrategia aparecen desarrolladas como una función de una serie de objetivos políticos, diplomáticos y económicos que, en su opinión, hacían necesario desencadenar un conflicto internacional, señalando así, de forma conceptual, la subordinación de la guerra a la política. Es por estas razones que la teoría estratégica de Macdonnell aparece entrelazada con una muy extensa descripción de planes de campaña concretos. El objetivo de estos planes era netamente práctico, pero reflejaba las ideas que el mismo autor había vertido en un voluminoso tratado teórico enteramente dedicado a la naturaleza de la guerra en el mar, el cual, según su propio testimonio, se perdió en un incendio. Como resultado, la expresión sistemática de su ideario teórico quedó inextricablemente ligada a un proyecto de guerra ofensiva que, pese a que fue seriamente considerado por la Secretaría de Marina como un posible plan de acción en 1804 y en 1816, resultó finalmente impracticable, quedando oculto como secreto de Estado y perdido para la historia del pensamiento estratégico hasta nuestros días.

El plan ofensivo de guerra y mar se hallaba enteramente basado en un mapa del Atlántico, América del norte y el Caribe, en el cual la bases logísticas de la Armada española quedaban unidas por medio de una línea «estacionaria» o "de primera posición». Esta debía articular una relación con las rutas transitadas por los buques mercantes del enemigo, en función de los vientos dominantes en cada punto de ellas, así como las corrientes y otras "causas locales, y mercantiles», representadas por los puertos que servían como bases principales de su comercio, así como las posibles rutas de comunicación entre ellos. En conjunto, estos elementos constituían "leyes fijas e imperiosas de la navegación", y su conocimiento hacía posible definir las acciones necesarias para alcanzar el objetivo de esta fase primera de la guerra naval: la destrucción del comercio enemigo. Esto debía obtenerse por medio de cruceros basados en los enclaves constituyentes de la línea estacionaria, los cuales debían situarse en las intersecciones de las «líneas de 
LA REPRESENTACIÓN HISTORIOGRÁFICA DE LA GUERRA EN EL MAR EN EL LARGO SIGLO XVIII...

movimiento» del tráfico adversario, definidas también como «esferas de actividad» mercantil. La línea de cruceros, en cambio, era denominada "de segunda posición" y reflejaba el despliegue de las fuerzas navales en función del tráfico marítimo del adversario, así como de las corrientes, las condiciones meteorológicas, la situación de las bases propias y la geografía costera de las ya mencionadas «esferas de actividad".

Una vez agotada la productividad de la guerra de corso, las fuerzas navales debían concentrarse y, en tres divisiones, formar una «línea de bloqueo» $\mathrm{O}$ "línea de tercera posición", situándose ante los enclaves portuarios de importancia decisiva para la economía mercantil del adversario. Macdonnell dedicó cierto empeño en describir la importancia de la disciplina en las fuerzas bloqueadoras para asegurar la efectividad de esta operación. En efecto, el bloqueo debía considerarse como una etapa final del plan de campaña, en la cual debían converger todas las líneas de operaciones dirigidas en contra del comercio. En contraste, los bloqueos de fuerzas navales demandaban la mayor cautela y solo podían ser eficaces en dos tipos de circunstancias. La primera era la ausencia de liderazgo en la escuadra bloqueada. La segunda era que la fuerza bloqueadora fuese decididamente superior $y$, en caso de existir fuerzas enemigas entre distintos puntos de bloqueo, que fuese posible asegurar la superioridad sobre cada una de ellas. El peligro residía en que las fuerzas bloqueadas lograran realizar una salida, reuniéndose en superioridad numérica, y negando la ventaja de la escuadra bloqueadora en ocupar una línea interior entre dos puertos.

Finalmente, cuando la guerra de corso y el bloqueo hubiesen cumplido su función de destruir la economía marítima del adversario, la campaña de mar debía entrar en coordinación directa con la campaña terrestre. Las fuerzas navales, concentradas en una sola fuerza o separadas en divisiones, según lo requiriesen las circunstancias, debían atacar las costas, bombardeándolas con ayuda de lanchas obuseras y cañoneras, y realizando desembarcos de infantería para devastar la infraestructura portuaria y sus recursos, impidiendo así toda recuperación de capacidad económica.

El pensamiento teórico de Madonnnell debe mucho a la obra del ya mencionado autor galés Henry Lloyd, y es enteramente coincidente con el método geométrico para trazar planes de campaña en función de la geografía. El autor aseguraba haber inventado este concepto en el caso de la guerra naval, pero también reconoció de manera explícita su deuda con Lloyd. En efecto, Macdonnell creía que los principios esenciales y sempiternos de la guerra podían ser aprehendidos por medio del genio personal, y que todos los grandes generales de la historia habían tenido un atisbo más o menos intuitivo de ellos. Significativamente, entre estos contaba a De Saxe, Schmidt y al ya mencionado archiduque Karl de Austria, pero también a varios responsables de la conducción de la guerra revolucionaria en Francia (Louis Alexandre Berthier, Thomas Alexandre Dumas, Pierre Dupont De l'Etang, Jean Joseph Desolles, Nicholas Oudinot, Lazare Carnot y Jean Claude Eléonore Le Michaud d'Arçon), por quienes profesaba una admiración 
LA REPRESENTACIÓN HISTORIOGRÁFICA DE LA GUERRA EN EL MAR EN EL LARGO SIGLO XVIII...

explícita. Es importante recordar que este planteamiento teórico forma parte de un plan de campaña concreto, cuya primera parte consistía en operaciones terrestres, las cuales, según su autor, debían ser llevadas a cabo de manera decisiva y, por utilizar una categoría anacrónica, también «total». En efecto, Macdonnell proponía negar la capacidad de recuperación del adversario, por medio de la destrucción sistemática de su infraestructura económica y la presión sobre sus poblaciones. Es en este sentido que deben ser comprendidas sus precauciones ante la posibilidad de ser considerado como un filósofo. Para Macdonnell, la abstracción teórica de la guerra debía servir a un propósito eminente práctico, es decir, político y operacional y, solo en segunda instancia, también formativo. Así, el objetivo didáctico de su manuscrito era reducir a "reglas fijas e invariables» la naturaleza y la práctica de la guerra en el mar, su aspecto "sublime", con la finalidad no solo de permitir la formulación de futuros planes de campaña con certeza científica, sino también instruir a nuevas generaciones de oficiales en los principios de la "ciencia nueva" de la estrategia de tierra y de mar. En sus palabras: "Señalo allá en el horizonte de lo posible, la existencia de una ciencia, que si bien ha existido siempre, no ha sido todavía bien devisada ni conocida. Esta ciencia es la Estrategia o la parte sublime de la guerra, sea de mar sea de tierra..." ${ }^{15}$.

\section{El SURGIMIENTO DE LA TEORÍA MILITAR «CIENTÍFICA» DEL SIGLO XIX: JOMINI}

Tras el fin de las Guerras Napoleónicas, la teoría militar europea dio un nuevo paso hacia la sistematización geométrica de la táctica terrestre y la «estrategia científica». Su más plena definición se encuentra en la vasta producción bibliográfica del historiador franco-suizo Henri-Antoine de Jomini ${ }^{16}$. Se trata de un oficial que prestó servicio en los ejércitos francés y ruso en períodos críticos de aquellos conflictos, quien, a partir de la lectura de Henry Lloyd y sus sucesores intelectuales, buscó perfeccionar la metodología concebida para sintetizar la naturaleza de la estrategia a partir del estudio pormenorizado de la historia operacional de las campañas napoleónicas, en una abstracción conceptual dedicada, en primera instancia, al nivel táctico, y extendida posteriormente al nivel estratégico. A diferencia de Lloyd, Karl y Von Bülow, quienes habían basado sus conclusiones en el estudio de la guerra dinástica del siglo XVIII, Jomini buscó sintetizar las claves fundamentales de la "guerra total" surgida de la Revolución francesa. Así, el estudio de la táctica adquirió nueva relevancia para la definición conceptual de la estrategia: la batalla de aniquilación, habiendo sustituido a la intención incruenta de la maniobra dieciochesca, pasó a representar la clave para la obtención de resultados decisivos a nivel estratégico. Con esto, el antiguo término de "líneas de operación",

15. Madrid, Museo Naval, MS. 435, fol. 142.

16. Jomini, Antoine de. The Art of War. Trad. de G. H. Mendell et W. P. Craighill. New York: Greenwood Press, s/d. 
dividido ahora en los subconceptos de "líneas interiores» y "líneas exteriores», adquirió el sentido de herramienta necesaria para lograr el objetivo último de la nueva estrategia científica: la "concentración de fuerza" en el "punto decisivo" del sistema militar del adversario.

A partir de este punto, la abstracción de los principios fundamentales de la táctica y la estrategia, basada en su separación de los múltiples aspectos de orden político, cultural, administrativo, material y financiero que constituyen el fenómeno social de la guerra, quedó consolidada como modelo dominante en la escritura de la historia militar. En este sentido, la profesionalización académica de esta disciplina durante el último tercio del siglo xIX puede ser considerada una función del utilitarismo inherente al método jominiano, potenciado en el contexto de la cientifización de las ciencias sociales en los sistemas universitarios europeos y auspiciado por la incorporación de los estudios históricos en el currículum formativo de las corporaciones de oficiales, todo lo cual contribuyó poderosamente a su relativo aislamiento académico ante la progresiva renovación humanística y diversificación metodológica de las ciencias sociales durante la primera mitad del siglo xx. De manera no menos importante, el culto a la personalidad napoleónica, implícito en el romanticismo cientificista del autor franco-suizo -Napoleón como la encarnación sublimada de la capacidad de aprehender la naturaleza científica de la táctica y la estrategia a través del genio personal-, se convirtió en otro componente definitorio de la historiografía militar, en la forma de la biografía operacional de los grandes comandantes.

La influencia de Jomini en los objetivos, alcances y métodos de la historiografía militar de los siglos XIX y Xx ha sido tan grande que, pese al olvido casi total de su nombre, logró incluso eclipsar el mensaje humanístico y filosófico contenido en la obra del otro gran teórico del arte militar moderno, Carl Von Clausewitz, el cual ha sido aprehendido por generaciones de lectores como una variante de la preceptiva táctica y estratégica inherente al método jominiano ${ }^{17}$. Así, el legado de Jomini puede ser considerado el paradigma intelectual dentro del cual tuvo lugar el desarrollo de la historiografía internacional dedicada a la guerra naval durante este período. En efecto: a partir de la última década del siglo XIX, la percepción de la importancia del estudio de la historia naval como fundamento intelectual de la estrategia comenzó a tomar nueva forma bajo la influencia de los estudios estratégicos desarrollados en los Estados Unidos.

17. Clausewitz, Carl von. De la guerra. México: Editorial Colofón, 1999. 
LA REPRESENTACIÓN HISTORIOGRÁFICA DE LA GUERRA EN EL MAR EN EL LARGO SIGLO XVIII...

9. LA TRANSFERENCIA DEL MÉTODO DE JOMINI AL ESTUDIO DE LA HISTORIA NAVAL: Alfred THAYER MaHAN Y LA IDEA DE LA INFLUENCIA DEL PODER NAVAL EN LA HISTORIA

El método de Jomini fue transferido al ámbito de la historia naval a través de la obra del oficial de la Armada estadounidense dedicado a la enseñanza de la historia: el capitán Alfred Thayer Mahan. Partiendo del estudio de los conflictos navales de la Antigüedad, Mahan desarrolló un aparato teórico concebido en función de la idea de que el "poder naval" representa un factor histórico relevante, no considerado hasta entonces en el estudio de las relaciones internacionales. Posteriormente, aplicó este modelo al estudio de la competencia entre los grandes imperios marítimos de la temprana Edad Moderna: España, las Provincias Unidas de los Países Bajos, Francia y Gran Bretaña. Es preciso señalar que la obra de Mahan poseía un claro interés propagandístico, cuya finalidad era convencer a su propio Gobierno de aumentar el gasto público en las fuerzas navales. Este debía ser el punto de partida de una política exterior expansiva, basada en la apropiación de colonias y en el desarrollo del comercio de exportación, en contraste con el aislacionismo internacional seguido hasta entonces por los Estados Unidos ${ }^{18}$.

Los elementos fundamentales de la interpretación mahaniana de la historia moderna se hallan contenidos en una trilogía, de la cual tan solo la primera parte suele ser conocida por los lectores no especializados. La primera parte, titulada The Influence of Sea Power upon History $(1890)^{19}$, está dedicada al período comprendido entre los albores de la Segunda Guerra Anglo-Holandesa (1660-1664) y el fin de la guerra de Independencia de los Estados Unidos (1660-1783). La segunda parte, titulada Influence of Sea Power upon the French Revolution and Empire $(1892)^{20}$, está dedicada al período definido por las guerras de la Francia Revolucionaria y Napoleónica (1792-1815). La tercera publicación lleva por título The Life of Nelson: The Embodiment of the Sea Power of Great Britain (1897) ${ }^{21}$ y está dedicada a la carrera del oficial que, según Mahan, supo interpretar a través de su genial inspiración la naturaleza sempiterna del poder naval, hasta lograr, en una decisiva batalla de aniquilación, la culminación de la competencia marítima internacional del largo siglo XVIII 22 .

18. Como punto de partida, véase Hattendorf, John. A Bibliography of the Works of Alfred Thayer Mahan. Newport: Naval War College Press, 1986.

19. MAHAN, Alfred Thayer. The Influence of Sea Power upon History, 1660-1783. Boston: Little Brown, 1890.

20. MAHAN, Alfred Thayer. The Influence of Sea Power upon the French Revolution and Empire, 1793-1812. London: Sampson Low, 1892, 2 vols.

21. MAHAN, Alfred Thayer. The Life of Nelson: The Embodiment of the Sea Power of Great Britain. Boston: Little Brown, 1897.

22. Sumida, Jon Tetsuro. Inventing Grand Strategy and Teaching Command. The Classic Works of Alfred Thayer Mahan Reconsidered. Baltimore: The John Hopkins University Press, 1997. 
El éxito internacional de esta trilogía residió en la presentación de un paralelo marítimo con la teoría militar desarrollada a partir de la experiencia continental de las Guerras Napoleónicas. Mahan estudió sistemáticamente a Jomini al inicio de su carrera como profesor de historia en el Colegio de Guerra Naval de Newport, Rhode Island, a mediados de la década de $1880^{23}$. La influencia del autor franco-suizo se manifestó, particularmente, en la adaptación naval del concepto táctico de "concentración de fuerza en el punto decisivo", lo cual, a su vez, se tradujo en la idea de que la clave del éxito en la guerra en el mar reside en la posesión de un "poder irresistible», cuyo empleo prohíbe al enemigo el acceso a las líneas de comunicación o le permite aparecer en ellas «tan sólo como un fugitivo». La implicación es clara: según Mahan, únicamente el "control militar del mar", por medio del "dominio prolongado de los centros estratégicos del comercio", puede ser considerado un instrumento bélico decisivo, el cual, a su vez, solo puede ser obtenido por medio de la superior potencia de fuego producida por la concentración de buques de guerra especializados en puntos neurálgicos de la infraestructura marítima del adversario. Se trata, efectivamente, de la adaptación del concepto de "concentración de fuerza en el punto decisivo", objetivo último de la estrategia jominiana, a la práctica de la guerra en el mar. De acuerdo con esta lógica, el poder naval solamente puede ser ejercido con eficacia trascendente por flotas de batalla especializadas, en la búsqueda a ultranza de la batalla decisiva, lo cual, a su vez, representa una abstracción de los preceptos de la guerra de escuadra, concebida según los principios tácticos emanados de las guerras Anglo-Holandesas de la segunda mitad del siglo XVII ${ }^{24}$.

La importancia de la batalla decisiva en el ideario mahaninano se halla subsumida en el más amplio concepto de "Sea Power", compuesto, a su vez, tanto por la dimensión socioeconómica del uso del mar (el "poder marítimo»), como por la variante marítima del poder militar (el "poder naval»). Este doble concepto, a su vez, aparece representado como producto de una serie de factores históricos no directamente relacionados con el uso del mar, pero que representan un punto de partida necesario para su desarrollo: la posición geográfica, la conformación física del litoral, la extensión del territorio, la densidad de la población, su "carácter»y, finalmente, el "carácter» de su gobierno e instituciones nacionales ${ }^{25}$. Estas condiciones llevaron al autor a señalar la existencia de un supuesto "orden natural» e inmutable en los principios estratégicos, presente en todas las épocas y, como primum mobile, susceptible de ser aprehendido por medio del estudio "científico» de las operaciones navales. Es precisamente en esta relación con el «orden inmutable de

23. Gough, Barry M. "The Influence of History on Mahan». En HatTENDORF, John. The Influence of History on Mahan, The Proceedings of a Conference Marking the Centenary of Alfred Thayer Mahan's "The Infuence of Sea Power Upon History, 1660-1783". Newport: Naval War College Press, 1991, pp. 17-18.

24. SumidA, Jon Tetsuro. Inventing Grand Strategy and Teaching Command, op. cit., pp. 24, 43.

25. MAHAN, Alfred Thayer. Influencia del Poder Naval en la historia. Madrid: Ministerio de Defensa, 2007, pp. 95-148. 
LA REPRESENTACIÓN HISTORIOGRÁFICA DE LA GUERRA EN EL MAR EN EL LARGO SIGLO XVIII...

las cosas» que reside, según Mahan, el origen de la perennidad de los principios estratégicos, así como su entera independencia con respecto a otros factores sujetos a la transformación de las condiciones históricas, principalmente, el desarrollo de la tecnología y, por ende, de la táctica naval ${ }^{26}$.

La consecuencia de la aplicación de este razonamiento, inherentemente jominiano, al análisis de los conflictos librados entre Francia, España y Gran Bretaña entre los siglos XVII y XIX es que el sistema naval británico, comprendido desde la perspectiva de solo uno de sus componentes estratégicos (la guerra de escuadra), aparece representado como el ejemplo paradigmático del poder naval, y su triunfo sobre la escuadra franco-española, en la batalla de Trafalgar (21 de octubre de 1805), como el punto culminante de la historia naval en el período clásico de la navegación a vela. De todo esto se desprende que otras formas de estrategia practicadas por los sistemas navales francés y español, específicamente la guerra de corso (empresarial y de Estado), son descritas por Mahan como mecanismos inferiores, de eficacia tan solo relativa; de efecto desgastante, pero no decisivo, e incluso como fuente de sufrimiento innecesario para las poblaciones marítimas de beligerantes y neutrales. Más aún, según el autor, el uso del corso como instrumento estratégico, en su variante empresarial, solo podía tener efecto suficiente bajo la protección de flotas de batalla. Así, estos elementos aparecen representados, en la dimensión teórica del pensamiento mahaniano, como estrategias subsidiarias de la guerra de escuadra, es decir, de la flota de batalla especializada y la búsqueda de enfrentamientos decisivos ${ }^{27}$.

La combinación de líneas de análisis desarrollada por Mahan, aunada a su presentación en la forma de un modelo teórico adaptable a todas las épocas, así como su descripción de la experiencia británica como el ejemplo supremo de la interacción concertada entre la actividad estatal y la economía marítima, contribuyeron poderosamente a que la recepción de su obra en las academias navales del mundo anglófono fuese extremadamente positiva. De hecho, su enorme éxito contribuyó al eclipse de autores que, en principio, compartían sus puntos de vista, y que actuaron vigorosamente para asegurar que el Gobierno británico retomase los principios del navalismo radical conocido como «estrategia de agua azul» ${ }^{28}$. Es preciso considerar que los primeros representantes de la escuela británica de estrategia naval (como los hermanos Colomb, Julian Corbett y Herbert Richmond) fueron relativamente eclipsados por la emergencia del paradigma mahaniano ${ }^{29}$, mientras que el caso de

26. Huges. Wayne P. «Mahan, Tactics and Principles of Strategy». En HaTtendorf, John. The Influence of History on Mahan, op. cit., pp. 25-37.

27. SumidA, Jon Tetsuro. Inventing Grand Strategy and Teaching Command, op. cit., pp. 43, 45.

28. LindBerg, Michael y TodD, Daniel. Brown-, Green-and Blue-Water Fleets. The Influence of Geography on Naval Warfare, 1861 to the Present. London: Praeger, 2001.

29. Véanse CorbetT, Julian S. Principles of Maritime Strategy. Mineola, New York: Dover Publications Inc., 1911; y England in the Seven Years War : a study in combined strategy. London: Longmans, 1907. Para los exponentes de la escuela británica, véanse Till, Geoffrey. "Corbett and the emergence of 
Edward Calwell señaló su plena adopción por la historiografía naval británica ${ }^{30}$. En contraste, el caso de Julian Corbett es significativo, pues la evolución de su pensamiento entre la publicación de su obra teórica Some Principles of Maritime Strategy (1911), así como su estudio dedicado a la dimensión naval de la guerra de los Siete Años (1907), demuestran una perspectiva no exclusivamente definida por la estrategia de aniquilación descrita por Mahan. Pese a ello, la perspectiva mahaniana se convirtió en un fenómeno historiográfico dominante en el mundo anglófono. Esto generó, a partir de la década de 1930, una nueva vertiente de estudios sobre táctica, ejemplificados por la obra de Carr Laughton ${ }^{31}$ y Brian Tunstall ${ }^{32}$, en Gran Bretaña, y por S. S. Robinson, en los Estados Unidos ${ }^{33}$. De manera paralela, los pensadores navales de las potencias europeas en expansión -en particular, la Alemania guillermina, el Japón Meiji y la Rusia zarista- adoptaron las ideas de Mahan como punto de partida para la formulación de sus respectivas estrategias navales, particularmente, durante el período que antecedió al estallido de la Primera Guerra Mundial ${ }^{34}$.

La historiografía naval francesa, por otra parte, fue comparativamente menos permeada por el navalismo histórico generado por la influencia de Mahan en la historiografía. Es posible que esto se debiera a la competencia de las ideas estratégicas y tácticas de la Jeune École, desarrolladas a partir del último tercio del siglo XIX por las obras teóricas de Richild Grivel y Théodore Aube, popularizadas por el publicista Gabriel Charmes y sujetas a la crítica del análisis histórico por la obra de Raoul Castex, a principios del siglo xx. Sus principales postulados apuntaron hacia una readaptación de los principios fundamentales de la estrategia naval francesa, basada, a diferencia de las ideas de Mahan, en la eficacia de la práctica de desgaste económico derivada de la tradicional guerra de corso, concebida en función de los avances tecnológicos de la segunda mitad del siglo XIX: el perfeccionamiento de la propulsión a vapor, la construcción en acero y, particularmente, la invención del torpedo. Tal vez no resulte exagerado señalar que el impacto de sus ideas entre los medios navales franceses contribuyó a la sofisticación de sus estudios dedicados a la guerra de corso. Así, la influencia del pensamiento estratégico en la historiografía se manifestó también en el caso francés, aunque la propuesta de

a British school?». En TILl, Geoffrey. The Development of British Naval Thinking. Milton Park: Routledge, 2006, pp. 60-87; y "Richmond and the faith reaffirmed: British naval thinking between the wars". Ibid., pp. 103-133; HATTENDORF, John. "The Study of War History at Oxford, 1862-1990». En HaTTENDORF, John. The Limitations of Military Power. New York, 1990, pp. 3-62.

30. Callwell, Charles Edward. The Effect of Maritime Command on Land Campaigns since Waterloo. Edinburgh and London: William Blackwood and Sons, 1897.

31. Véanse sus numerosas publicaciones en la revista The Mariner's Mirror.

32. Tunstall, Brian (Editado por Nicholas Tracy). Naval Warfare in the Age of Sail: The Evolution of Fighting Tactics, 1650-1815. London: Wellfleet, 2001. El texto fue escrito en la década de 1930.

33. Robinson, S. S. y Robinson, Mary L. A History of Naval Tactics From 1530 to 1930. The Evolution of Tactical Maxims. Annapolis, Maryland: The United States Naval Institute, 1942.

34. SondHAus, Lawrence. Navies in Modern World History. London: Reaktion books, 2004; LisLE, Rose. The Age of Navalism, 1890-1918. Columbia: University of Missouri Press, 2007. 
LA REPRESENTACIÓN HISTORIOGRÁFICA DE LA GUERRA EN EL MAR EN EL LARGO SIGLO XVIII...

la Jeune École, como alternativa al énfasis en la guerra de escuadra y la batalla decisiva propia del pensamiento de Mahan, tuvo por efecto hacer que la diversidad de modelos estratégicos y su vinculación con el estudio de la historia operacional tuviese diferente eco en la historiografía de ese país ${ }^{35}$.

En suma, tal como en el caso de la influencia de Jomini en estudio de la historia militar, el ideario de Mahan y sus intérpretes de diversos países dejó de ser identificado como una etapa específica en el desarrollo del pensamiento estratégico y la historiografía, perdiéndose la vinculación con su contexto y autores, y contribuyendo así a la consolidación de un paradigma negativo en la percepción académica y popular de la experiencia naval franco-hispana del largo siglo XVIII.

\section{LA INFLUENCIA DE MAHAN EN LA HISTORIOGRAFÍA NAVAL HISPANA DE LOS SIGLOS XIX Y XX}

Durante el primer tercio del siglo XIX, la desintegración del sistema imperial y la profunda crisis de la Armada española señalaron el ocaso de la teoría táctica y estratégica en el mundo hispano. Estas líneas de pensamiento, extintas, dieron paso a la historiografía naval, la cual, en su origen, también puede explicarse en función de consideraciones pragmáticas. Efectivamente, las primeras formas de narrativa operacional dedicadas al siglo XVIII tuvieron su origen en discursos de perspectiva histórica, concebidos como argumentos para la reforma del sistema naval, en tres períodos identificables: el primero fue el contexto inmediatamente posterior a la batalla de Trafalgar; el segundo, la crisis imperial generada por la invasión napoleónica de 1808; y el tercero, el período definido por las guerras de independencia en la América hispana. Esta tendencia puede considerarse terminada con la publicación, en 1839, de la primera narrativa operacional de carácter general, por Juan Miguel de los Ríos.

Durante la segunda mitad del siglo XIX, el sistema naval español experimentó una recuperación gradual. Una nueva política exterior concebida para recuperar el prestigio internacional por medio del desarrollo del poder naval, aunada a la corriente intelectual del hispanoamericanismo, generó un ambiente cultural propicio para el renacimiento de la historiografía operacional como disciplina intelectual separada de objetivos pragmáticos de carácter militar. Así, vieron la luz las obras de Manuel Marliani (1850), José Ferrer de Couto (1851) y José March y Llabores (1854), cuya característica más relevante es el énfasis en el estudio de las grandes

35. GRIVEL, Richild. De la guerre maritime avant et depuis les nouvelles inventions. Paris: Arthus Bertrand, 1869. Couttau-Bégarie, Hervé. La Potencia Maritima (Castex). Madrid: Ediciones Ejército, 1985; CASTEX, Raoul. L'envers de la guerre de course. San Bernardino: Michigan Library, 2013; y Les idées militaires de la marine du XVIIIe siècle. San Bernardino: University of Michigan Library, 2013. Véase Ropp, Theodore. The Development of a Modern Navy. French Naval Policy 1871-1904. Annapolis: Naval Institute Press, 1987; RøKsund, Arne. The Jeune Ecole: The Strategy of the Weak. Leiden: Brill, 2007. 
LA REPRESENTACIÓN HISTORIOGRÁFICA DE LA GUERRA EN EL MAR EN EL LARGO SIGLO XVIII...

batallas navales, Lepanto y Trafalgar, como claves históricas necesarias para comprender al auge y decadencia de la hispanidad. Resulta significativo que la segunda de estas batallas, Trafalgar, haya sido representada como la culminación de la trayectoria histórica del mundo hispano como actor marítimo global.

Esta tendencia historiográfica alcanzó un alto grado de sofisticación en la pluma del gran polígrafo Cesáreo Fernández Duro (1830-1908). Su obra magna, Armada española, fue escrita precisamente en los mismos años en que Mahan produjo su trilogía dedicada a la influencia del poder naval en la historia. Sin embargo, tal como en el caso de los difusores del pensamiento histórico de la Jeune École, Fernández Duro realizó importantes contribuciones al estudio de los distintos modelos estratégicos desarrollados por la España imperial no solo durante el período borbónico, sino desde el establecimiento mismo de la monarquía. Su distancia del navalismo histórico puede ser explicada por el hecho de que escribió en un contexto de acelerada renovación del material flotante de la Armada. Cuatro programas de construcción naval sucesivos (Pavía, 1883; Antequera, 1884; Moret, 1885; Ley Rodríguez Arias, 1887) señalaron una transición táctica hacia los preceptos de la Jeune École ${ }^{36}$, mientras que la obra del publicista Joaquín Costa (1887) impulsó la integración de la industria naval en la vida pública del país, promoviendo una gran estrategia que vinculaba el poder naval con el desarrollo económico por medio del fomento a la industria nacional, el comercio exterior, el desarrollo del hispanoamericano y el establecimiento de colonias en África ${ }^{37}$. Así, la historia naval se convirtió en un importante componente de la cultura política de este período, un fenómeno manifiesto en la fundación de la Revista General de Marina, en 1877, y de la Liga Naval Española, en 1900.

A partir de la guerra con los Estados Unidos, en 1898, tuvo lugar una notable intersección de la historiografía naval española con el navalismo histórico derivado de la lectura de Mahan. En efecto, la obra del analista naval Joaquín Sánchez de Toca sentó las bases de una interpretación de la historia del mundo hispánico en clave talasocrática de larga duración, definida por la idea de que la intervención del Estado en las industrias marítimas como fundamento del poder naval representó un factor positivo para el desarrollo de la hispanidad, en contraste con los períodos de orientación estratégica de orden fundamentalmente militarista y continental. Esta idea de la historia del mundo hispano se hallaba definida por una visión negativa del presente, derivada de la representación de las derrotas navales de 1588 y 1805 como claves interpretativas del devenir histórico de la hispanidad, en un sentido altamente pesimista ${ }^{38}$.

36. Rodríguez González, Agustín. Política naval de la Restauración (1875-1898). Madrid: Editorial San Martín, 1988, pp. 163-175, 236-237.

37. Costa, Joaquín. Marina española o la cuestión de la escuadra. Huesca: Establecimiento Tipográfico de Leandro Pérez, 1912, pp. 53-72.

38. SÁNCHEZ DE ToCA, Joaquín. Del poder naval en España y su política económica para la nacionalidad Iberoamericana. Madrid: Imprenta de los Hijos de M. G. Hernández, 1898, pp. 11-12, 
LA REPRESENTACIÓN HISTORIOGRÁFICA DE LA GUERRA EN EL MAR EN EL LARGO SIGLO XVIII...

Pese a que el objetivo de Sánchez de Toca no era otro que utilizar el discurso histórico como fuente de legitimación ideológica para un acelerado proceso de reforma económica, sus ideas tuvieron una profunda, y tal vez involuntaria, influencia en la representación histórica de la experiencia marítima de la hispanidad durante prácticamente todo el siglo xx. Varias condiciones contribuyeron a ello. La primera fue el desenlace de la guerra con los Estados Unidos ${ }^{39}$, percibido como una confirmación fáctica de la interpretación anglocéntrica de la competencia internacional de los siglos XVIII y XIX, directamente derivada de las obras de Mahan. La segunda fue la traducción al español de la primera obra del teórico estadounidense, en 1901, con un estudio introductorio que reproducía puntualmente la interpretación pesimista de Sánchez de Toca ${ }^{40}$. La tercera fue la apertura de un intenso debate público sobre las funciones y naturaleza de la Armada en el contexto político de la posguerra inmediata, potenciado por el ascenso del mismo Sánchez de Toca a la cartera de Marina en el Gobierno conservador de $1903^{41}$. Es en este contexto inmediato que la batalla catastrófica volvió a ser un tópico central en la narrativa operacional española, con la publicación de la ya mencionada $E l$ combate de Trafalgar, de Pelayo Alcalá Galiano, en 1909, así como de las historias generales de Montero Sánchez ${ }^{42}$, Navarrete y Alcázar ${ }^{43}$ y De la Guardia ${ }^{44}$.

La historiografía española dedicada a la guerra naval tuvo un marcado hiato entre las dos guerras mundiales, aunque se publicaron numerosas obras

15, 71-76, 212-232, 233-256.

39. Véase MORTERA PÉrez, Artemio. 1898. Corazas y cañones. Aspectos de la guerra naval con los Estados Unidos. Gijón: Fundación Alvargonzález, 2008.

40. MAHAN, Alfred Thayer. Influencia del Poder Naval en la Historia, 1660-1783. Trad. Juan Cervera y Jácome y Gerardo Sobrini y Angullos. El Ferrol: Imprenta de El Correo Gallego, 1901, pp. II, XIII, XVI, XVIII.

41. Rodríguez GonZÁlez, Agustín. La reconstrucción de la escuadra. Planes navales españoles, 1898-1920. Madrid: Galland Books, 2010, pp. 43-76; SERrano MonTEAVARO, Miguel Ángel. «El poder naval en la España de entresiglos 1890-1907\%. Militaria. Revista de Cultura Militar, 1990, n. ${ }^{\circ}$ 2. CERVERA PerY, José. "Sánchez de Toca y el poder naval». En Plan Ferrándiz: poder naval y poder marítimo: Madrid: Instituto de Historia y Cultura Naval. Cuaderno n. ${ }^{\circ}$ 57, 2008, pp. 11-18; De LA VeGA, Antonio. "El plan de escuadra Maura-Ferrándiz». En Plan Ferrándiz: poder naval y poder marítimo, op. cit., pp. 19-37; Álvarez LAITA, Javier. «Implicaciones industriales del Plan Maura-Ferrándiz». En Plan Ferrándiz: poder naval y poder marítimo, op. cit., pp. 65-86. Cabe señalar que incluso las ideas del influyente publicista Joaquín Costa, precursor, como hemos señalado, del pensamiento navalista español, quedaron trastocadas por esta interpretación de la historia. Véanse CosTA, Joaquín. "En defensa del ejército y la marina». En op. cit., pp. 74, 98-99; VIAÑa REMís, Enrique. "iPantanos o acorazados? Economía y defensa en la España del novecientos». En CAYUELA Fernández, José G. (ed.). Un siglo de España: centenario 1898-1998. Cuenca: Universidad de Castilla/Universidad de La Habana, p. 322.

42. Mintero Sánchez, Antonio. Compendio de la historia de la marina militar de España. Madrid: Suc. de Rivadeneyra, 1900.

43. NAVARrete y AlCÁZAR, Adolfo. Armada española y marinas que le antecedieron. Madrid: Suc. de Rivadenayra, 1901.

44. GuARDiA, Ricardo de la. Datos para un cronicón de la Marina de guerra española. Madrid: 1912. 
LA REPRESENTACIÓN HISTORIOGRÁFICA DE LA GUERRA EN EL MAR EN EL LARGO SIGLO XVIII...

dedicadas a otros temas marítimos que no corresponden a los objetivos de este ensayo $^{45}$. La segunda posguerra, en cambio, trajo consigo un repunte de la narrativa operacional de larga duración, la mayor parte no exclusivamente dedicada al siglo XVIII, pero sí de dimensión propiamente naval y, en ciertos casos, de dimensión específicamente estratégica ${ }^{46}$. El caso de la ya mencionada Revista General de Marina es relevante, puesto que sus análisis de contenidos demuestran una importante producción de artículos dedicados a la teorización táctica contemporánea, mientras que el primer artículo de teoría estratégica que critica explícitamente la ortodoxia mahaniana fue publicado en $1966^{47}$. Es importante señalar que también se publicaron un gran número de estudios de historia de la táctica naval, de abstracción teórica y alto nivel de detalle, pero no dedicados al período cubierto por el ensayo, sino a los siglos XVI y XVII, los cuales representan, en todo caso, lecturas valiosas para la especialización en historia naval. Por otra parte, el número de artículos dedicados a la historia operacional del siglo XVIII, en su nivel táctico, demuestran la preponderancia de esta temática en relación de otras áreas de la historia marítima y naval del siglo xx. En efecto: el recuento bibliográfico realizado en 1994 por Carla Rahn Phillips indica que, dentro del conjunto de publicaciones dedicadas a la historia marítima y naval hispánica del siglo XVIII hasta ese momento, en todas sus áreas, la narrativa de batallas ocupaba prácticamente la tercera parte del total de la muestra ${ }^{48}$. Por otra parte, la fundación de la Revista de Historia Naval, en 1983, y de su complemento en la forma de los Cuadernos Monográficos del Instituto y Cultura Naval, a partir de 1999, han abierto la historia naval a áreas diversas de las humanidades ${ }^{49}$. De manera paralela, la creación de los Cuadernos de Pensamiento Naval, en 2001, han abierto una nueva veta para la reflexión histórica en el marco de los estudios estratégicos contemporáneos.

45. La excepción es la historia general de Francisco de Condeminas Mascaró, titulada La marina militar española desde los orígenes hasta 1898. Málaga, 1930. Hay una reimpresión: Málaga: Aljaima, 2000.

46. IBÁÑEZ DE IBERO, Carlos, Marqués de Mulhacén. Historia de la Marina de Guerra española desde el siglo XIII hasta nuestros dias. España: Espasa-Calpe, s. a., 1939; Fernández Almagro, Melchor. Política naval de la España moderna y contemporánea. Madrid: Instituto de Estudios Políticos, 1946; ESTRADA Y ARNAIZ, Rafael. La influencia del mar en la historia de España. Zaragoza: Institución Fernando el Católico [CSIC] de la Diputación Provincial, 1950; NAVARRo GONZÁlez, Victoriano. La Marina en la vida de España. [S. I., s .n.], 1955; CEREzo MARTínez, Ricardo. España y el poder marítimo. Madrid: Editora Nacional, 1975; Bordejé y MoRencos, Federico Fernando. España, poder marítimo y estrategia naval. S. 1.: Empresa Nacional Bazán de Construcciones Navales Militares, 1982: Cervera PerY, José. La marina de la Ilustración: resurgimiento y crisis del Poder Naval. Madrid: San Martín, 1986.

47. Blanco NúÑEZ, José María. "Centenario de la RGM: táctica y buques». En VV. AA. La Revista General de Marina y su proyección histórica. Madrid. Cuadernos Monográficos del Instituto de Historia y Cultura Naval, 10, 1990, pp. 27-32.

48. Philipps, Carla Rahn. En HatTEndorf, John (ed.). Ubi Sumus? The State of Naval and Maritime History. Newport, Rhode Island: Naval War College Pres, 1994, pp. 325-343.

49. Para una visión general: CEPEDA GÓMEZ, José. "La historiografía sobre la marina en los siglos XVIII y XIX". Cuadernos Monográficos del Instituto de Historia y Cultura Naval, 2008, 56, pp. 123-145. 
LA REPRESENTACIÓN HISTORIOGRÁFICA DE LA GUERRA EN EL MAR EN EL LARGO SIGLO XVIII...

11. LA TRANSFORMACIÓN DE LA HISTORIOGRAFÍA NAVAL ENTRE LOS SIGLOS XX Y XXI: NUEVAS PERSPECTIVAS METODOLÓGICAS EN EL ESTUDIO DE LA TÁCTICA Y LA ESTRATEGIA NAVAL DEL LARGO SIGLO XVIII

El predominio del militarismo y navalismo históricos de los siglos XIX y XX corrió de manera paralela al inicio de una transformación gradual de temáticas y metodologías en el estudio de la historia militar la cual, lentamente, llevó el estudio de la guerra al corazón mismo de las humanidades y las ciencias sociales. Con esto, los estudios de táctica y estrategia cesaron de ser percibidos exclusivamente como un apéndice de la formación de oficiales o como un resabio de paradigmas decimonónicos en la historiografía, sino como un tema relevante para los estudios en humanidades. Se trata de un fenómeno de dimensión internacional que, como veremos en este último apartado, comenzó a intersectar con el hispanismo dieciochista hacia finales del siglo xx, generando una extraordinaria renovación profesional de la historia militar, la cual ha definido una dimensión importante de la producción historiográfica del siglo XXI en distintos contextos universitarios.

El punto de partida puede situarse con la obra del historiador alemán Hans Delbrück, quien, en un amplio estudio dedicado al arte de la guerra en la Antigüedad, la Edad Media, el siglo XVI y el largo siglo XVIII ${ }^{50}$, utilizó el antiguo principio metodológico de correlación entre los dispositivos tácticos y la naturaleza de las constituciones políticas, esbozado por primera vez en la Política de Aristóteles; desarrollado por Polibio y Vegecio, y recuperado en el Renacimiento por el fundador de la ciencia política moderna, Nicolás Maquiavelo, en su obra fundamental El arte de la guerra. El objetivo de Delbrück, tal como el de sus predecesores clásicos, era reflexionar sobre la forma en que determinadas formas de organización para la guerra inciden en los procesos formativos de las instituciones públicas, señalando posibles paralelos entre las formas de organización de la infantería y los sistemas administrativos creados para su reclutamiento, mantenimiento y logística. En este sentido, su obra dio inicio a una corriente historiográfica que buscó interpretar los procesos formativos del Estado moderno a través del estudio de la administración económica de los sistemas militares. De manera convergente, Otto Hintze desarrolló de manera explícita la hipótesis de la correlación entre sistemas militares y sistemas políticos en el contexto de la temprana Edad Moderna, señalando que toda organización estatal moderna ha sido, en su origen, una forma de organización para la guerra ${ }^{51}$. Por otra parte, la orientación jominiana manifiesta en el estudio de batallas decisivas dio paso a una reflexión al respecto de la incidencia del legado clásico en la organización del combate de infantería,

50. Geschichte der Kriegskunst im Rabmen der politischen Geschichte, publicada entre $1900 \mathrm{y}$ 1908. Existe una traducción inglesa: History of Warfare in the Framework of Political History. University of Nebraska Press, 1990, 4 vols.

51. "Military Organization and State Organization». En GILBERT, Felix. The historical essays of Otto Hintze (1975). Oxford: University Press, 1975, pp. 157-177. 
LA REPRESENTACIÓN HISTORIOGRÁFICA DE LA GUERRA EN EL MAR EN EL LARGO SIGLO XVIII...

como clave para comprender la capacidad de los sistemas militares europeos para resistir la expansión de otras civilizaciones. Es precisamente en este sentido que el historiador británico Charles Oman acuñó el término de "Revolución Militar», para referirse a la acelerada transformación de los dispositivos tácticos durante la primera mitad del siglo XVI, los cuales habrían hecho posible la contención del poder militar otomano en Europa central ${ }^{52}$.

Esta línea de interpretación, basada en la idea de la periódica aparición de «revoluciones tecnológicas» en la táctica de infantería, así como en su caracterización como un mecanismo impulsor de la transformación de las constituciones políticas, constituyó el fundamento de una importante corriente en los estudios clásicos de la primera mitad del siglo xx, cuyo origen se remonta al modelo explicativo del surgimiento de la polis griega desarrollado por Max Weber en Economía y Sociedad (publicada de manera póstuma en 1921 y 1922) ${ }^{53}$. Esta vertiente historiográfica, conocida como "Teoría de la Revolución Hoplita», ha alcanzado la posición de verdadero debate teórico-historiográfico en el siglo $\mathrm{XXI}^{54}$. Entre sus componentes se cuenta la importancia del poder naval para comprender el surgimiento de los sistemas democráticos, tanto en la Antigüedad clásica como en la temprana Edad Moderna ${ }^{55}$.

Esta corriente historiográfica adquirió una importante dimensión económica, al incorporar a sus interpretaciones la dimensión financiera de los sistemas logísticos y sus transformaciones a partir de las demandas impuestas por la evolución de las técnicas de combate, en distintos períodos. En particular, esta vertiente de pensamiento económico fue transferida a los estudios dedicados a la guerra en la temprana Edad Moderna por el economista austríaco Joseph Schumpeter, quien, en un influyente ensayo titulado "Die Krise der Steuerstaates", publicado en 1918, argumentó que el surgimiento de los ejércitos profesionales de la temprana Edad Moderna, compuestos por grandes masas de individuos apartados de manera

52. OMAn, Charles. History of the Art of War in the Middle Ages. London: Meuthen, 1924; History of the Art of War in the Sixteenth Century. London: Meuthen 1937.

53. México: Fondo de Cultura Económica, 2014.

54. Para una síntesis del debate, véase ECHEVERría Rey, Fernando. Ciudadanos, campesinos y soldados: el nacimiento de la pólis griega y la teoría de la revolución hoplita. Madrid: Ediciones Polifemo, 2008. Para su dimensión naval: SABIN, Phillip. The Cambridge History of Ancient Warfare. Cambridge: University Press, 2007; FAGAN, Garret y Trunde, Matthew (eds.). New Perspectives on Ancient Warfare. Leiden: Brill, 2010; TARN, William Woodthorpe. Hellenistic Military and Naval Developments. Cambridge: University Press, 2010; Murray, William M. The Age of the Titans. The Rise and Fall of the Great Hellenistic Navies. Oxford: University Press, 2012.

55. ReYNOLDS, Clark G. "Thalassocracy" as a Historical Force». En ReYNOLDS, Clark G. History and the Sea. Essays on Maritime Strategies. Columbia: University of South Carolina Press, 1989, pp. 20-65; VAN WeES, Hans. "Those Who Sail Are To Receive a Wage: Naval Warfare and Finance in Archaic Eretria». En FAGAn, Garret y Trundle, Matthew (eds.). New Perspectives on Ancient Warfare. Leiden: Brill, 2010, pp. 205-226; LAMBERT, Andrew. Seapower States. Maritime Culture, Continental Empires and the Conflict that Made the Modern World. New Haven: Yale University Press, 2018. 
permanente de los procesos productivos por las necesidades de la disciplina y el entrenamiento militar, generó la necesidad de crear sistemas administrativos para la transferencia de excedentes económicos generados por otros sectores de la población, contribuyendo así al surgimiento de la fiscalidad pública o, en otras palabras, al "Estado Fiscal». Este ensayo, traducido al inglés en 1954, junto con la difusión internacional de la obra de Max Weber, constituyó el fundamento intelectual para el desarrollo de una teoría del surgimiento del Estado moderno como una función de las transformaciones de la táctica de la infantería a partir de la introducción de las armas de fuego ${ }^{56}$. Esta puede considerarse como la filiación intelectual de uno de los textos más influyentes de la historiografía militar académica del siglo xx, la conferencia leída por el historiador Michael Roberts en 1955, en la Universidad de Belfast, titulada "The Military Revolution, 1550-1660 „57. Con ello, las ideas al respecto de la importancia de la táctica para comprender la formación del Estado fueron situadas en el contexto de la guerra de los Treinta Años, señalando la transferencia de dispositivos concebidos para la incorporación sistemática de las armas de fuego a las formaciones de infantería pesada, desde la rebelión de los Países Bajos a los ejércitos suecos de Gustavo Adolfo, como un detonador del proceso formativo del Estado moderno.

A partir de estos procesos intelectuales, la tecnología, específicamente la naturaleza y evolución de los dispositivos tácticos, comenzó a ocupar una posición central en los estudios universitarios dedicados a la historia militar. La desde entonces llamada «Teoría de la Revolución Militar» fue ampliamente desarrollada por la trayectoria intelectual del historiador estadounidense Geoffrey Parker, así como por un extenso debate historiográfico que involucró a especialistas de distintas áreas de la historia de Europa a lo largo de la década de $1990^{58}$. Su importancia es crucial, puesto que, al ampliar el espectro de tecnologías consideradas como potenciales catalizadores del cambio hacia las prácticas extremadamente costosas de la fortificación, la construcción naval y la navegación oceánica, amplió también el marco cronológico del debate a los siglos XV y XVI, con lo cual, la centralidad del mundo hispánico en el proceso de construcción de la modernidad resultó evidente para los especialistas de distintos países. Esta línea de razonamiento fue consolidada por el historiador británico Jeremy Black, quien centró sus líneas de investigación no en la introducción de las armas de fuego, sino en la reintroducción de las tácticas de infantería pesada en las guerras de Italia (1494-1559), con

56. SCHUMPETER, Joseph. «The Economics and Sociology of Capitalism». En BackHAus, Jürgen G. (ed.). Navies and State Formation. The Schumpeter Hypothesis Revisited and Reflected. Berlin/Zurich: LIT, 2012, pp. 21-62.

57. RoBerTs, Michael. "The Military Revolution, 1550-1660». En Rogers, C. (ed.). The Military Revolution Debate. Readings on the Transformation of Early Modern Europe. Oxford: West View Press, 1995, pp. 13-36.

58. Rogers, C. (ed.). The Military Revolution Debate. Readings on the Transformation of Early Modern Europe. Oxford: West View Press, 1995. 
LA REPRESENTACIÓN HISTORIOGRÁFICA DE LA GUERRA EN EL MAR EN EL LARGO SIGLO XVIII...

lo cual el protagonismo fundamental de la hispanidad en el desarrollo ulterior del debate quedó consolidado 59 .

La trascendencia de la Teoría de la Revolución Militar no puede ser exagerada, incluso a resultas de la crítica emergida a principios del siglo XXI por parte de algunos de sus propios protagonistas. La utilidad analítica del concepto se encuentra vigente en la medida que su incorporación al estudio de la expansión oceánica de Europa ha sido recuperada por diversos estudios dedicados a la globalización temprana. En efecto, las interpretaciones dedicadas a la integración económica entre Europa y Asia han debido recurrir, de manera más o menos explícita, a conceptos clave de esta teoría para explicar el fenómeno de la "gran divergencia» entre esas dos regiones del mundo. Por otra parte, el concepto de "Revolución Militar en el Mar» ha sido retomado de manera más o menos precisa por varios especialistas en historia marítima, pero su aplicación más directa ha sido obra de Michael Palmer, quien, siguiendo los presupuestos fundamentales de la Teoría de la Revolución Militar, ha caracterizado la introducción de la artillería de andana, así como el perfeccionamiento de su uso en la forma de la línea de batalla durante las guerras Anglo-Holandesas, como la dimensión marítima de una revolución tecnológica directamente relacionada con el incremento de la intervención estatal en la industria de la construcción naval y en la fiscalización del comercio $^{60}$. Esta lectura, sin embargo, debe mucho a la abstracción de la táctica de sus aspectos contextuales, y quizás puede ser considerada como una de las últimas manifestaciones del pensamiento mahaniano en la escritura reciente de la historia naval ${ }^{61}$.

Es preciso considerar que la erosión del modelo mahaniano comenzó a resultar evidente para otras áreas de los estudios universitarios a partir de la publicación de la obra del estadounidense Paul Kennedy The Rise and Fall of British Naval Mastery, en 1976, así como de las actas de dos importantes conferencias internacionales dedicadas a las implicaciones historiográficas de los estudios estratégicos, en 1991 y $1993^{62}$. Con esto, la importancia de la estrategia descentralizada

59. Black, Jeremy. European Warfare 1660-1815. London and New York: Routledge Taylor and Francis Group, 2003; y War in European History 1494-1660. Washington, D.C.: Potomac Books, Inc., 2006.

60. Palmer, Michael. "The "Military Revolution" Afloat: The Era of the Anglo-Dutch Wars and the Transition to Modern Warfare at Sea». War in History, 1997, 4, pp. 123-149; y Command at Sea. Cambridge, Massachussets: Harvard University Press, 2005.

61. Tunstall, Brian. Naval Warfare in the Age of Sail: The Evolution of Fighting Tactics, 1650-1815. London: Welfleet, 2001; LAVERY, Brian. The Line of Battle: Sailing Warships, 1650-1840. Conway Maritime Press, 2004.

62. Kennedy, Paul M. The Rise and Fall of British Naval Mastery. London: Penguin Books. National Maritime Museum, 2004; HATTENDORF, John B. (ed.). The Influence of History on Mahan. The Proceedings of a Conference Marking the Centenary of Alfred Thayer Mahan's 'The Influence of Sea Power Upon History, 1660-1783. Newport, Rhode Island: Naval War College Press. Diane Publishing 
LA REPRESENTACIÓN HISTORIOGRÁFICA DE LA GUERRA EN EL MAR EN EL LARGO SIGLO XVIII...

de la guerra de corso cobró nueva fuerza en los estudios académicos de historia naval $^{63}$.

Este mismo sentido, la obra del estadounidense John Hattendorf ha tenido el importante efecto de llamar la atención a los historiadores de diversos países al respecto de la relatividad de los alcances de la obra de Mahan, así como de la importancia de otros exponentes del pensamiento estratégico del siglo xx como fundamento para la comprensión de la historiografía naval contemporánea ${ }^{64}$. Así, en Francia, Cristian Buchet, Jean Meyer y Jean-Pierre Poussou han ofrecido una nueva perspectiva global del poder naval en su dimensión estratégica ${ }^{65}$, mientras que, en el ámbito específico de la táctica naval, Nicholas Rodger y Sam Willis han realizado severas críticas a los estudios basados exclusivamente en la legislación o en la tratadística, en detrimento de la documentación producida por oficiales con experiencia práctica en el mando de navíos individuales o escuadras ${ }^{66}$.

A partir de 1989, la evolución de la historiografía dedicada a las conexiones entre los sistemas militares y la formación del Estado comenzó a dar un giro importante, con un gradual abandono del análisis tecnológico y un renovado énfasis en la construcción de la fiscalidad pública a partir de necesidades logísticas. Esta línea metodológica, inaugurada por el historiador británico John Brewer en el caso del sistema militar inglés del siglo XVIII bajo el concepto de "Fiscal-Military State» ${ }^{67}$, pronto extendida al caso del mundo hispano, entre otros, por la monumental obra del sueco Jan Glete ${ }^{68}$. La utilidad analítica de estos conceptos fue confirmada con la formación, en 2004, de un grupo de investigación internacional dedicado a diversos aspectos del sistema militar y naval hispano del siglo xviII, iniciado por la colaboración entre los historiadores españoles Agustín González Enciso y Rafael Torres Sánchez, en una serie de obras que hoy representan el referente esencial

Co., 1991; HATTENDORF, John y GOLDRICK, James. Mahan is not enough. Newport, Rodhe Island: Naval War College Press, 1993.

63. Bromley, John Selwyn. Corsairs and Navies 1600-1760. London: Hambledon Press, 1987; STARKEY, David. The British Privateering Enterprise in the Eighteenth Century. Exeter: Maritime Studies, 1990; VILLIERS, Patrick. Marine Royale, corsaires et trafic dans l'Atlantique de Louis XIV a Louis XVI. Lille: Atelier National de Reproduction de Thèses, 1992, 2 vols.; Vergé-Franceschi, M. y GrAzIANI, Antoine-Marie. La guerre de course en Méditerranée (1515-1830). París-Ajaccio: PUPS Paris-Sorbonne-Éditions Alain Piazzola, 1999.

64. HatTendorf, John B. (ed.). Doing Naval History. Essays Toward Improvement. Newport, Rhode Island: Naval War College Press, 1995.

65. Buchet, Christian; Meyer, Jean y Poussou, Jean-Pierre. La puissance maritime. Paris: PUPS Paris-Sorbonne, 2003.

66. RoDGER, Nicholas. "Image and Reality in Eighteenth Century Naval Tactics». The Mariner's Mirror, 2013, 89, 3, pp. 289-296; WILlis, Sam. Fighting at Sea in the Eighteenth Century. The Art of Sailing Warfare. Woodbridge: The Boydell Press.

67. Brewer, John. The Sinews of Power: War, Money, and the English State, 1688-1783. New York: Knopf, 1989.

68. GleTE, Jan. Navies and Nations: Warships, Navies and State Building in Europe and America, 1500-1860. Estocolmo: Almqvist and Wiksell, 1993, 2 vols. 
LA REPRESENTACIÓN HISTORIOGRÁFICA DE LA GUERRA EN EL MAR EN EL LARGO SIGLO XVIII...

para la reflexión en torno a la relación de la guerra y la formación del Estado, en el contexto del sistema imperial español del siglo XVIII ${ }^{69}$. Por otra parte, el concepto de "Fiscal Military State» se convirtió en un referente de la historiografía naval británica durante este mismo período, en un proceso sintetizado por la acuñación del término «Fiscal-Naval State» por parte de Nicholas Rodger, en 2011

Durante la segunda década del siglo XXI, la estrecha colaboración entre los principales exponentes de la metodología del Estado Fiscal-Militar o Fiscal-Naval, en Gran Bretaña y España, ha dado por resultado la superación conceptual de esta corriente, por parte de sus propios protagonistas. En efecto, del lado británico, las obras de Martin Wilcox/Roger Knight ${ }^{71}$ y Richard Harding ${ }^{72}$, y de los ya citados Rafael Torres Sánchez, Agustín González Enciso y Sergio Solbes Ferri ${ }^{73}$, del lado hispano, han señalado, desde diversas perspectivas de la logística y financiamiento de los sistemas navales del siglo XVIII, las enormes posibilidades metodológicas de la transferencia del enfoque metodológico desde la fiscalidad estatal hacia la contratación de procesos productivos. En contraste con las metodologías de la Revolución Militar y del Estado Fiscal-Militar/Naval, enfocadas en el proceso de construcción del Estado desde la perspectiva tecnológica o de la administración financiera, las metodologías del "Contractor State» o "Estado Contratante» buscaron responder a la necesidad de comprender las formas de interacción entre la Administración pública con los procesos productivos relacionados con el aprovisionamiento y manutención de las fuerzas armadas, de tierra y de mar, en prácticamente todos los niveles. En este sentido, la distorsión relativa introducida por centrar el análisis histórico en la construcción del Estado, así como en su capacidad para intervenir procesos productivos anteriormente controlados por agentes privados, ha sido sustituida por el

69. Bowen, Huw y GonZÁLEz Enciso, Agustín. Mobilising Resources for War. Britain and Spain at Work during the Early Modern History. Pamplona: Ediciones de la Universidad de Navarra, 2006; GoNZÁlEZ ENCISO, Agustín. Un Estado militar. España, 1659-1820. Madrid: Actas, 2012; y War, Power and the Economy. Mercantilism and State Formation in 18th-Century Europe. London: Routledge, 2017. Torres SÁnchez, Rafael y Conway, Stephen. The Spending of States. Saarbrücken: VDM Verlag Dr. Müller, 2011; TorRes SÁNCHEZ, Rafael. War, State and Development. Fiscal-Military States in the Eighteenth Century. Pamplona: Eunsa, 2008; El precio de la guerra: el Estado Fiscal-Militar de Carlos III. Madrid: Marcial Pons, 2013; Constructing a Fiscal-Military State in Eighteenth-Century Spain. London: Pallgrave Macmillan, 2015; Military Entrepreneurs and the Spanish Contractor State in the Long Eighteenth Century. Oxford: University Press, 2016.

70. RODGER, Nicholas. "From the "Military Revolution" to the "Fiscal-Naval State" . Journal for Maritime Research, 2011, 13, 2, pp. 119-128.

71. Knight, Roger y Willcox, Martin. Sustaining the Fleet: War, the British Navy and the Contractor State. Woodbridge: Boydell Press, 2010; "War, Government and the Market: The Direction of the Debate on the British Contractor State, c. 1740-1815". En HaRding, Richard y Solbes, Sergio. The Contractor State and its Implications, 1659-1815. Las Palmas: Universidad de Gran Canaria, 2012, pp. 169-192.

72. HARDING, Richard. "Contractors, Warships of the Royal Navy and Sea Power, 1739-1748". En HARDing y SOlBes. Op. cit., pp. 153-167.

73. Solbes, Sergio. «Introduction». En Harding y SOlBes. Op. cit., pp. 7-17. 
LA REPRESENTACIÓN HISTORIOGRÁFICA DE LA GUERRA EN EL MAR EN EL LARGO SIGLO XVIII...

énfasis en la dimensión de la actividad empresarial con la Administración pública, demostrando la fluctuante relación entre ambas durante el largo siglo XVIII.

La transición de la historiografía militar y naval desde una disciplina fuertemente influida por los estudios estratégicos a un área de estudios central para la comprensión del surgimiento del Estado y el desarrollo de la economía y la industria es el contexto necesario para comprender la diversificación de la historiografía dedicada a la táctica y la estrategia naval entre los siglos xx y xxI. En efecto, la historiografía naval británica dio importantes pasos en este sentido con la publicación, por parte de Richard Harding ${ }^{74}$, Nicholas Rodger ${ }^{75}$ y Roger Knight ${ }^{76}$, de una serie de importantes estudios de síntesis dedicados al ejercicio del poder naval en el siglo XVIII, situando el desarrollo de la estrategia dentro de estos parámetros interpretativos ${ }^{77}$. En el caso hispano, esto ha permitido una nueva valoración de la estrategia como un área de acción política y militar definida no solamente por los intereses y los objetivos de la Monarquía, sino también por su capacidad de interactuar con los centros productivos regionales ${ }^{78}$.

74. HARDING, Richard. Seapower and naval warfare, 1650-1830. UK: UCL Press Taylor and Francis Group, 1999; "Naval Warfare 1453-1826». En BlACK, Jeremy (ed.). European Warfare 1453-1815. New York: Palgrave Macmillan, 1999, pp. 96-117; "Trans-Atlantic Operational Capability: State, Resources and War 1739-1748”. En Bowen, H. V. y González Enciso, A. (eds.). Mobilising Resources for War..., pp. 177-195.

75. Rodger, N. A. M. The Command of the Ocean. A Naval History of Britain, 1649-1815. London: Penguin Books. National Maritime Museum, 2004.

76. Knight, Roger. Britain Against Napoleon. London: Allen Lane, 2013.

77. Para el caso británico, véanse los siguientes ensayos historiográficos: RoDGER, Nicholas. "Recent Books on the Royal Navy of the Eighteenth Century». The Journal of Military History, Jul. 1999, vol. 63, n. ${ }^{\circ}$ 3, pp. 683-703; KNIGHT, Roger. "Changing the Agenda: The "new" Naval History of the British Sailing Navy». The Mariner's Mirror, 2011, 97: 1, pp. 225-242. Para una perspectiva francesa e internacional: JAMES, Alan. "Raising the Profile of Naval History: An international perspective on early modern navies». The Mariner's Mirror, 2011, 97, 1, pp. 193-206.

78. BAudot Monroy, María. "Asientos y política naval en el inicio de suministro de víveres a la armada en el inicio de la guerra contra Gran Bretaña, 1739-1741". Studia Historica. Historia Moderna, 2013, 35, pp. 127-158; «El regreso de Felipe V a Italia después de la Guerra de Sucesión. La expedición anfibia hispano-inglesa a la Toscana». Revista Universitaria de Historia Militar, 2016, 5/1, pp. 67-88; "La Hacienda de Marina entre la neutralidad de Fernando VI y la movilización de Carlos III en 1760». En Rodríguez HERnÁNDEZ, Antonio José et al. (eds.). Comercio, guerra y finanzas en una época en transición (siglos XVII-XVIII). Valladolid: Castilla, 2017, pp. 195-223; "La expedición naval contra Argel de 1733". En TORRES SÁNCHEZ, Rafael (coord.). Studium, magisterium et amicitia: bomenaje al profesor Agustín González Enciso. Pamplona: Eunate, 2018, pp. 369-377; "La política naval española entre 1700 y 1736. La recuperación del poder naval de la Monarquía». Tempus Revista en Historia General, 2019, 9 , pp. 1-50; GonzÁlez EnCISO, Agustín. «La escuadra de Ferrol, 1733». En BAudot Monroy, María. El Estado en guerra. Expediciones navales españolas en el siglo XVIII. Madrid: Polifemo, 2014, pp. 25-59; "La Marina hacia la conquista de Italia, 1733». Cuadernos Monográficos del Instituto de Historia y Cultura Naval, 2014, 69, Madrid, pp. 15-35; TORRES SÁNCHEZ, Rafael. "La movilización de recursos en la organización de la expedición anfibia de Menorca de 1781». Revista Universitaria de Historia Militar, 2016, 5, 10 (Ejemplar dedicado a La logística anfibia: el poder naval del Imperio español en el Mediterráneo durante el siglo XVIII), pp. 156-177; "Geoestrategia y recursos. El punto de partida en la expedición marítima 
LA REPRESENTACIÓN HISTORIOGRÁFICA DE LA GUERRA EN EL MAR EN EL LARGO SIGLO XVIII...

Esto se ha traducido, en años recientes, en una revaloración económica de la estrategia, como una forma de acción estatal definida fuertemente influida por la capacidad de interacción y negociación con agentes sociales capaces de proveer determinados productos o servicios. En este sentido, una nueva serie de estudios sobre estrategia militar y naval, dedicada a las implicaciones logísticas, administrativas y financieras de su puesta en práctica a nivel operacional, ha trascendido la anterior dimensión utilitaria, ideológica o metanarrativa, para convertirse en un elemento central de las interpretaciones sobre el desarrollo de la capacidad administrativa del Estado, de su relación con la fiscalidad y de su impacto en el desarrollo industrial y económico de las grandes potencias atlánticas del largo siglo XVIII. Este nuevo horizonte intelectual ha hecho posible una significativa diversificación temática en el estudio de la correspondencia entre principios estratégicos y dispositivos tácticos, incorporando la reflexión acerca de los parámetros de la guerra de escuadra y su interacción con la guerra de corso. Esta perspectiva de renovación temática puede vincularse a un creciente interés en la importancia estratégica del corso empresarial, particularmente durante las guerras de Independencia en Hispanoamérica, con estudios recientes publicados por David Head, Matthew MacCarthy, Nicolás Terrien y Feliciano Gámez Duarte ${ }^{79}$. Finalmente, en este renovado horizonte historiográfico, la introducción de elementos culturales y psicológicos como elemento para interpretar la formulación de la estrategia y la ejecución de la táctica ha tenido un lugar importante en la superación del énfasis jominiano en el genio personal de los comandantes $^{80}$.

del duque de Crillón a Menorca en 1781». En BAudot. El Estado en guerra..., pp. 261-292; RodRíGUEz HERNÁNDEZ, Antonio José. «Evolución o innovación? Los cambios técnico-tácticos en el armamento del ejército español durante el relevo dinástico: nuevas consideraciones». Cuadernos de Historia Moderna, 2016, 41, 2, pp. 273-294; VALDEZ-BuBNov, Iván. "La Batalla del Cabo Sicié. Implicaciones administrativas y doctrinales del uso de mercantes armados en el servicio naval». En BAUDOT. El Estado en guerra..., pp. 117-146; "Pensamiento táctico y liderazgo estratégico: la evolución de la doctrina naval española entre los siglos XVII y XVIII». En GuIMERÁ, Agustín (coord.). Liderazgo estratégico en España, 1475-2018. Madrid: UNED, 2019.

79. GÁmez DuARTe, Feliciano. Del uno al otro confin. España y la lucha contra el corso insurgente hispanoamericano, 1812-1828. Cádiz: Diputación Provincial, 2008; MCCARTHY, Matthew. Privateering, Piracy and British Policy in Spanish America, 1810-1830. London: Boydell Press, 2013; HEAD, David. Privateers of the Americas: Spanish American Privateering from the United States in the Early Republic. Athens: University of Georgia Press, 2015; Terrien, Nicolas. Des Patriotes Sans Patrie. Historie Des Corsaires Insurgés De L'Amérique Espagnole (1810-1825). Mordelles: Les Perséides Éditions, 2015.

80. Guimerá Ravina, Agustín. "Bloqueos navales y operaciones anfibias: la perspectiva Española». En Blanco NúÑEz, José María y Guimerá Ravina, Agustín (eds.). Guerra Naval en la Revolución y el Imperio. Bloqueos y operaciones anfibias 1793-1815. Madrid: Marcial Pons Historia, 2008, pp. 79-98; "La Marine Espagnole Contre La Piraterie Nord-Africaine (1750-1785)». En BATTESTI, Michèle (dir.). La piraterie au fil de l'histoire. Un défi pour l'État. Actes du colloque international, 9-12 mai 2012. Paris: PUPS, 2014, pp. 331-345; "Teoría y Práctica del Imperio: El Secretario de Marina e Indias Antonio Valdés en la Junta de Estado (1787-1792)». En Andalucía-España-Las Indias. Pasión por la Historia. 
En suma, durante el siglo xxI, el hispanismo internacional ha desarrollado nuevas perspectivas para la comprensión de los usos del poder naval como instrumento estratégico, así como de las implicaciones económicas y administrativas de su puesta en práctica. Esto representa un fenómeno de renovación historiográfica de gran envergadura, definido a partir de la superación del tecnocentrismo derivado de los estudios estratégicos y de su longevo predominio en la forma de la narrativa táctico-operacional.

Homenaje al profesor Antonio-Miguel Bernal. Sevilla: Editorial Universidad de Sevilla, Marcial Pons, 2015, pp. 513-543; "The Offensive Strategy of the Spanish Navy 1763-1808». En Dancy, J. Ross; DARNELL, Benjamin; Rodger, N. A. M. y Wilson, Evan (eds.). Strategy and the Sea. Essays in Honour of John B. Hattendorf. Woodbridge: The Boydell Press, 2016, pp. 98-108; "Principes Stratégiques et Défense de L'Empire Espagnol». En Chaline, Oliver y Guimerá, Agustín (dirs.). La Real Armada. Le Marine des Bourbons d'Espagne au XVIIIe siècle. Paris: PUPS, 2018, pp. 77-98; "La Stratégie Navale et la Navigation Espagnole ver Les Antilles et le Golfe Du Mexique (1759-1783)». En Bonnichon, Philippe; Chaline, Olivier y VERgEnNes, Charles-Philippe de (dirs.). Les Marine de la guerre d'Indépendance américaine (1763-1783) II. L'opérationnel naval. Paris: PUPS, 2018, pp. 67-90. 
